\title{
Fossil Energy in the Framework of Sustainable Development: Analysis of Prospects and Development of Forecast Scenarios
}

\author{
Yuriy Leonidovich Zhukovskiy ${ }^{1}{ }^{(}$, Daria Evgenievna Batueva $\left.{ }^{1}{ }^{(}\right)$, Alexandra Dmitrievna Buldysko ${ }^{1}$, Bernard Gil ${ }^{2}$ \\ and Valeriia Vladimirovna Starshaia ${ }^{1, *}$ \\ 1 Educational Research Center for Digital Technologies, Saint Petersburg Mining University, 2, 21st Line, \\ 191106 Saint Petersburg, Russia; spmi_energo@mail.ru (Y.L.Z.); dasha-batueva4@rambler.ru (D.E.B.); \\ abuldysko@mail.ru (A.D.B.) \\ 2 Laboratoire Charles Coulomb UMR 5221, CNRS-Université de Montpellier, 34095 Montpellier, France; \\ bernard.gil@umontpellier.fr \\ * Correspondence: lerastarshaya@gmail.com
}

check for updates

Citation: Zhukovskiy, Y.L.; Batueva, D.E.; Buldysko, A.D.; Gil, B.; Starshaia, V.V. Fossil Energy in the Framework of Sustainable Development: Analysis of Prospects and Development of Forecast Scenarios. Energies 2021, 14, 5268. https://doi.org/10.3390/en14175268

Academic Editors: Nuno

Carlos Leitão and François Vallée

Received: 24 June 2021

Accepted: 20 August 2021

Published: 25 August 2021

Publisher's Note: MDPI stays neutral with regard to jurisdictional claims in published maps and institutional affiliations.

Copyright: (c) 2021 by the authors. Licensee MDPI, Basel, Switzerland. This article is an open access article distributed under the terms and conditions of the Creative Commons Attribution (CC BY) license (https:// creativecommons.org/licenses/by/ $4.0 /)$.

\begin{abstract}
In the next 20 years, the fossil energy must become a guarantor of the sustainable development of the energy sector for future generations. Significant threats represent hurdles in this transition. This study identified current global trends in the energy sector and the prospects for the development of energy until 2035. The importance of risk assessment in scenario forecasting based on expert judgments was proven. Three contrasting scenarios, \#StayHome, \#StayAlone, and \#StayEffective, for the development of fossil energy, all based on comprehensive analysis of global risks by expert survey and factor analysis, were developed. It was concluded that fossil energy is mandatory with integration of advanced technologies at every stage of the production of traditional energy and of renewable energy as an integral part of the modern energy sector. Based on the results of the study, nine ambitious programs for the development of sustainable energy are presented. They require the creation and the utilization of a single interactive digital platform adapted to this purpose. It is a passport mandatory for the flexible interaction of energy production, its transmission, and its consumption in the perspective of having a future sustainable, reliable, and secured energy sector.
\end{abstract}

Keywords: sustainable energy development; fossil energy; renewable energy sources; digital technologies; energy transition; factor analysis; analysis of the scenario

\section{Introduction}

Developing countries that are rich in natural resources face vital challenges of economic diversification, resource replenishment [1], air quality maintenance, public health, and growing demands [2,3] for cheap energy and water resources. All of the above can be summarized as critical factors for energy and the environment [2]. The whole energy sector must become the guarantor of a "sustainable development" for our future generations as a basic substrate for meeting their needs. Achieving this can be difficult if states do not sufficiently support some specific sustainable development goals (SDGs) [4,5]. The 2030 agenda marks the first time in human history when the nations of the world must reach an agreement in terms of a comprehensive vision with clear goals and targets for the development of our civilization on planet Earth. Seventeen sustainable development goals (SDGs) were adopted by all governments of the world at the United Nations in 2015. Their goal is to guide the global development until 2030. The development of the fuel energy as part of these SDGs is considered, since the energy sector is one of the pillars of the economic development for the sustainable development of the world. To achieve these SDGs and for a safe use of fossil energy, the development and the integration of modern technologies [6,7] must be encouraged and supported at every stage of the production. The energy sector is only mentioned explicitly in the SDG "Affordable and Clean Energy". However, 
the sustainable development of fossil energy until 2035 requires the direct implementation of these nine out of the 17 SDGs, adopted by all UN member states in 2015 [8,9].

The choice and the justification of nine of the 17 SDGs for the conventional energy are based on some specific and identified current trends of the development of conventional fossil energy. The trends that are correlated with the SDGs are shown in Figure 1.

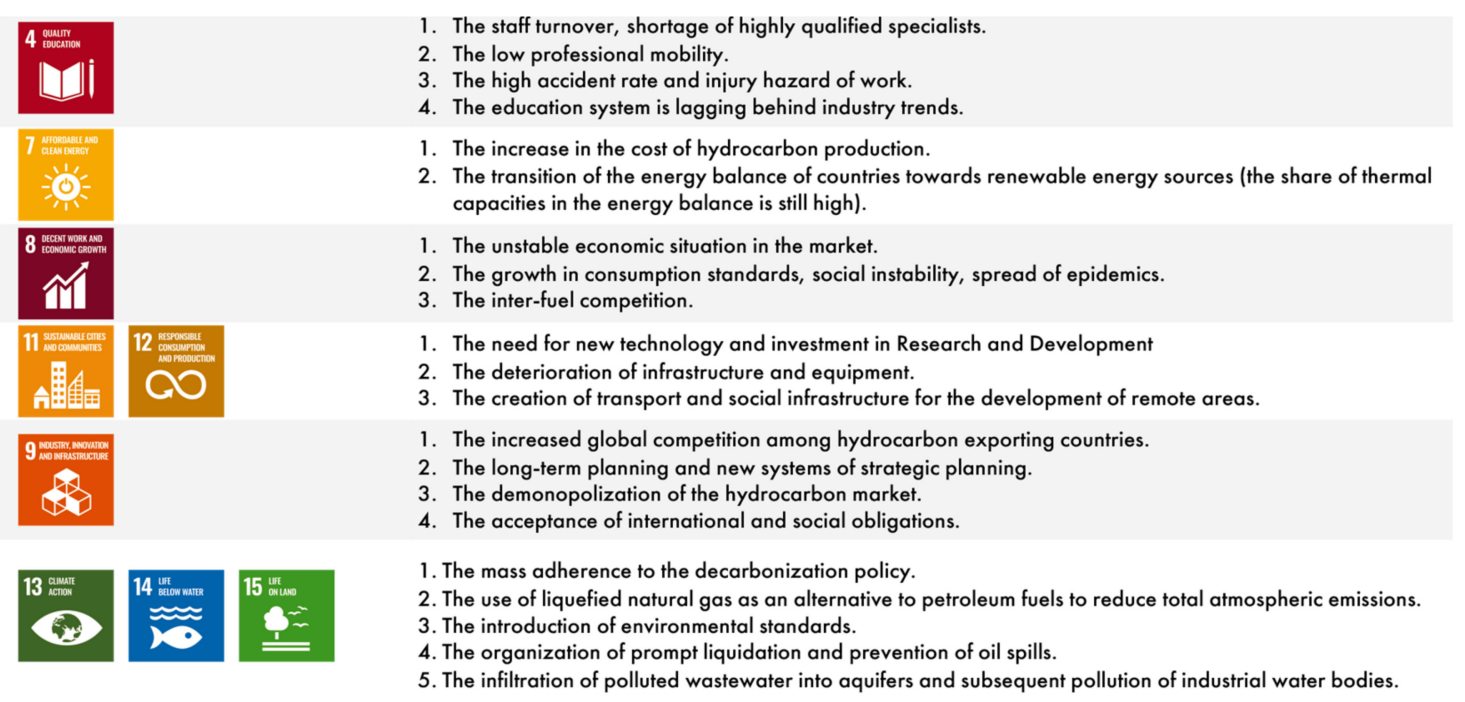

Figure 1. The rationale for choosing nine out of 17 SDGs in accordance with the modern trends in the fossil energy [4-9].

To avoid being vulnerable, states need to undertake a range of policies and practices in order to promote a global sustainable development [10]. Steps were taken to achieve SDGs 4, 8, 9, 11, and 12 in order to contribute to increased consumption and efficiency in terms of fossil energy, thus spurring the demand for its transformation in the course for the development of sustainable energy. However, the restrictions designed to achieve SDGs 7, 13,14 , and 15 contain volume growth and accelerate the pace of the energy transition to sustainable development.

In recent years, the growing role of renewable sources in the world of energy has led to a decrease in the relative importance of traditional energy resources. Renewable energy is becoming one of the key factors for the sustainability of society [11]. However, this energy is still far from being used universally. Most renewable energies suffer dramatic changes because of their dependence on climatic and economic conditions [12]. In this regard, the role and the possibilities of the energy transition through the growth of the renewable energy in many countries, including those currently under transition economies, remain unclear and require additional research.

The fossil fuels still cumulatively accounted for $84 \%$ of the primary energy consumption in the world in 2019 [11]. In this regard, and for the upcoming decades, the transition for the development of sustainable energy will be primarily ruled by an appropriate utilization of traditional energy. According to the British Petroleum World Energy Outlook published in 2019 and McKinsey Energy Insights Global Energy Perspective 2019, the global demand for hydrocarbons will continue to grow for the next 20 years until about 2040, but at a slower pace, and natural gas is the fastest growing source of energy in addition to renewable energy sources $[13,14]$.

Thus, the solution to recovery of the energy sector is partly based on the transition to renewable energy systems [11-14]. Moreover, most of the remaining potential of renewable energy is located in developing countries [15]. In many developing countries and in countries with transient economies, the renewable energy industry faces serious problems: (i) a lack of investments [10] and (ii) a low level of research and development in the energy sector [16]. This leads to a situation still in its infancy, which is highly dependent on policy and has low sensitivity to the external macro-environment [17]. In addition, the 
specific industry of renewable energy requires a large upfront investment combined with a long-term return on investment, both resulting in even higher risks compared to the industry of traditional energy.

This study focused on the technologies that are mandatory for the sustainable development of fossil energy. The emergence of digital industries and high-tech spaces enables transforming the approach to supply energy to consumers [18]. Achieving stability and reliability of power supply, increasing the throughput of electrical networks, and automating control over electricity consumption are goals made possible only through the use of radically new approaches, materials, and technologies. The digitalization of the energy sector is one of the key factors for the sustainable socio-economic development in the world [19-21]. The technological development in the field of digital and information technologies will create fundamentally new opportunities for improving the efficiency of fossil energy, as the impact of such technologies on the flexibility of process control systems is very noticeable today in the modern world. The widespread introduction of digital technologies will significantly reduce the response time to pressing economic challenges and requests as well as pressing consumer problems. However, the main difficulty of the digital transformation lies in the underdeveloped digital culture [22]. This requires new types of workers with competencies in new technologies that are reactive and capable of a fast adaption to the digital reality [23,24].

In this way, the goal of the study was to predict current global trends in the energy sector, technological trends in the industry of fossil energy, and prospects for development until 2035. Analysis of political, socio-cultural, economic, legal, technological, environmental, and commercial risks of the development of fossil energy was the basis for scenario analysis. The role of developing countries and countries with economies in transition in sustainable development of fuel energy is presented in the paper. During the study, negative, positive, and innovative scenarios for the development of fossil energy were developed on the basis of a comprehensive analysis of global risks proposed by expert survey using a factor analysis.

Today, almost all literature in the field of scenario forecasting focuses on considering options to responses to every specific scenario [8,25-28]. In this paper, we suggest an innovative generalized model for assessing the scenario risk for the choice of development programs regardless of emerging scenarios.

It is of scientific interest for SDG implementation and can be of great value for stakeholders who create programs and make decisions to implement them in the field of sustainable development of the energy sector.

Based on our findings after analysis of the predicting scenario, recommendations (strategies) were formulated for each of the three scenarios concerning the implementation of a policy of fossil energy. These programs were combined into a digital platform highlighting constraints and systemic and cross-cutting effects on fuel energy and the economy as a whole.

\subsection{The Key Role of the Developing Countries in the Sustainable Development of the Energy Sector}

The fossil energy sector is currently undergoing a difficult transition, and it requires the use of costly technologies to improve its production levels [29-31]. The energy systems must become more sophisticated and technologically advanced in terms of meeting the growing needs of the consumers for the reliability of energy supply and the quality of energy resources [32]. Based on the BP outlook 2020 and the McKinsey's Global Energy Perspective of 2019, a comparative analysis of the leading energy-producing countries for 2019 is presented in Figure $2[13,14]$. 

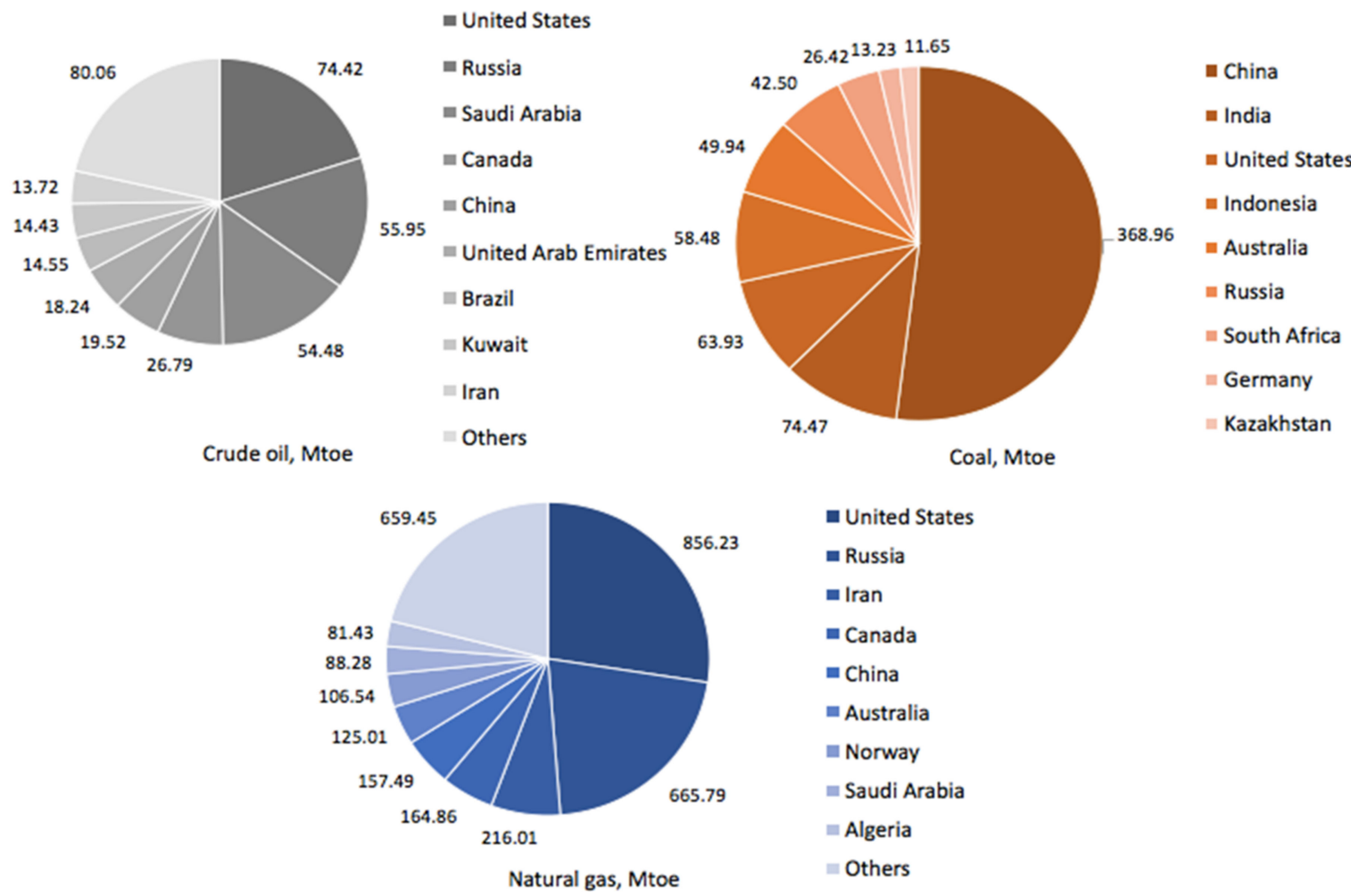

Figure 2. The leading countries in primary energy production for 2019. Crude oil: the chart shows the top nine countries and another 21 countries from the top 30 leaders combined into "others": Nigeria, Mexico, Kazakhstan, Norway, Algeria, Venezuela, United Kingdom, Colombia, Indonesia, India, Egypt, Argentina, Malaysia, Thailand, Australia, South Africa, Germany, Ukraine, Uzbekistan, Poland, Netherlands. Coal: the chart shows the top nine countries. Natural gas: the chart shows the top nine countries and another 21 countries in the top 30 leaders grouped into "others": Egypt, Malaysia, Indonesia, United Arab Emirates, Uzbekistan, Argentina, Kazakhstan, Nigeria, United Kingdom, Netherlands, India, Thailand, Brazil, Mexico, Ukraine, Kuwait, Venezuela, Colombia, Germany, Poland, South Africa. All countries are presented according to their rank in descending order of production $[13,14]$.

During this study, the productions of primary energy resources in 30 leading countries were analyzed. This confirmed the key role that developing countries can play in the sustainable development of the energy sector (Table 1). The parameter GDP PPP (gross domestic product with purchasing power parity) from 1990 until 2019 is given at current prices in dollars in the table. This parameter was used to determine the type of economic development of countries in the world.

Table 1. The role of emerging economies in the global production of energy [33-35].

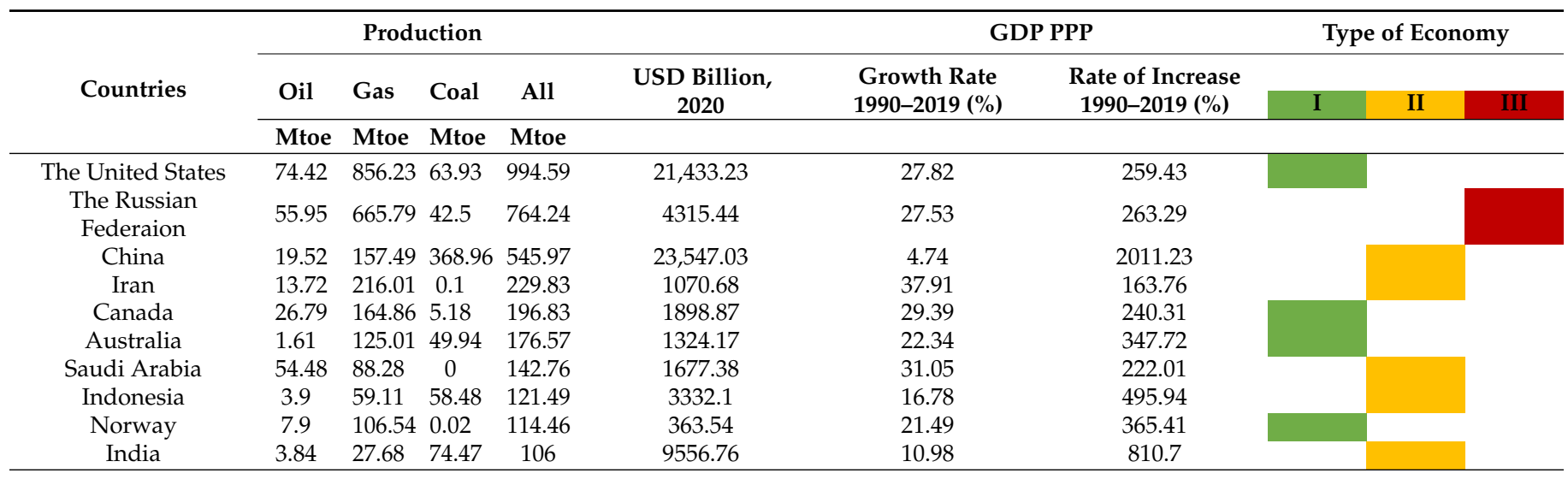


Table 1. Cont.

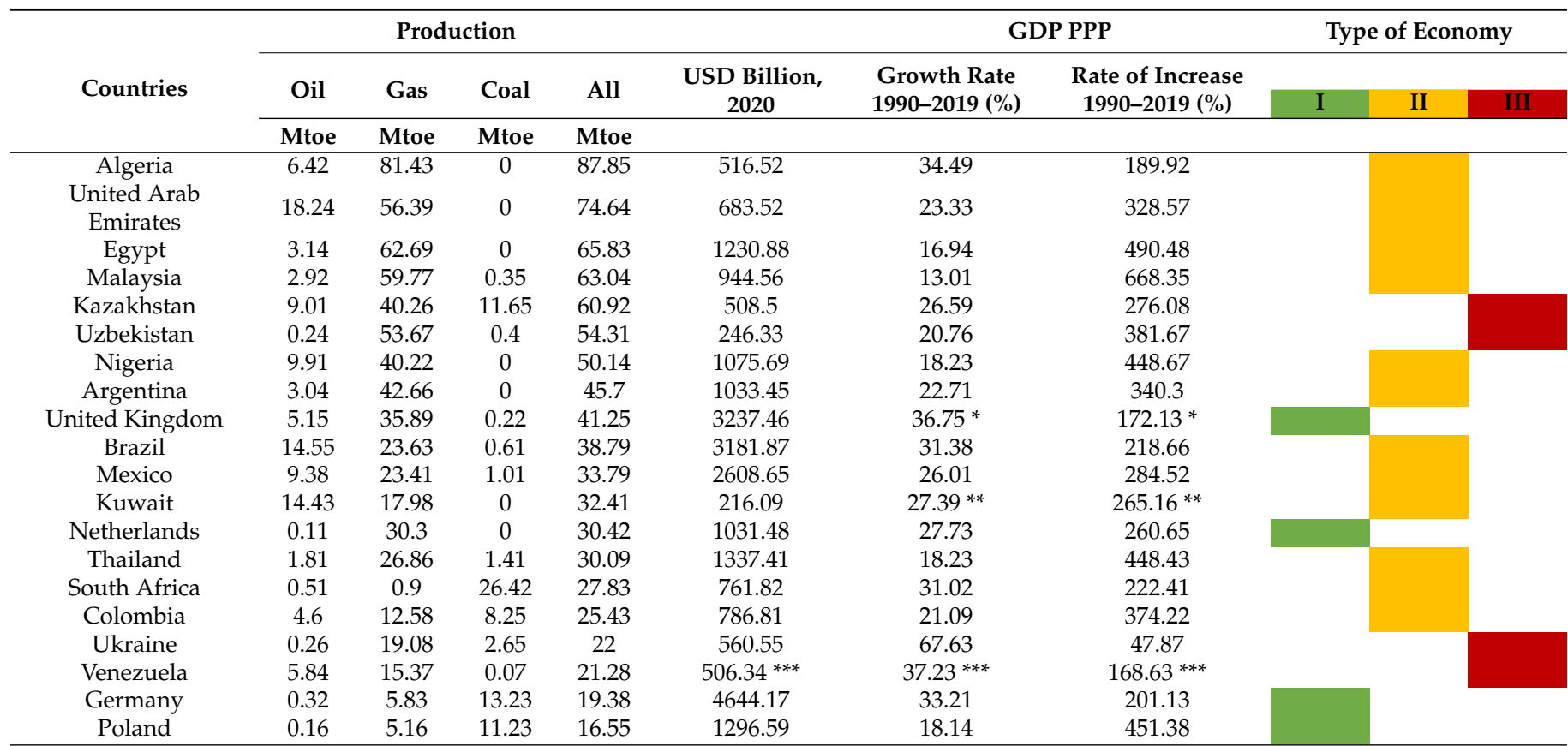

Economic development stages: I-developed. II—developing. III-transient. * GDP data available since $1995 .{ }^{* *}$ GDP data available since 1992. ${ }^{* * *}$ GDP data available until 2011.

The United States remains the leading country in production of traditional hydrocarbon resources $[35,36]$. However, $63 \%$ of the leading countries in primary energy productioncrude oil and natural gas-are under developing and transient economies [35,37]. This share is distributed among 22 countries. The Russian Federation has the second place in the production of traditional resources, and it is a country with a transient economy (Table 1). Share of this country in the world energy balance is $26 \%$. It is obvious that the development of a fossil energy sector of this country will play a key role in the transformation of the energy sector in the world [38].

In this way, the approach of this study was applied to the case of the Russian Federation. The purpose of the development of Russian fossil fuel energy is, on the one hand, to strengthen and maintain its position in the global socio-economic development, and, on the other hand, to strengthen and maintain its position in the global energy sector in addition to maintaining reliable quality and an economically sound supply of energy carriers and raw materials in regard to the principles of energy conservation and energy efficiency.

Thereby, the relevance of the transition to the sustainable development of fossil fuel energy in the Russian Federation is due not only to internal challenges but also to the need to provide a basis for sustainable development for the whole world. The key indicators of the energy exports in the context of global trends were presented for the Russian Federation in $[18,39-44]$.

\subsection{Properties of the Transformations of the Fossil Energy}

Rethinking the energy transition, year 2017 saw the formation of three trends shaping the future of energy, dubbed the three "Ds" [45]:

- Digitalization is changing the way the power system works; there is a new understanding of how electricity is used, how electricity is generated and delivered, and how plants and systems are built to generate, transport, distribute, and store the energy.

- Decarbonization is related to the climate as well as the primary fuel supply and electrification. It can also bring both economic and environmental benefits. 
- Decentralization is linked to the changes in industries and to trends in the distribution of the energy consumption towards more small economic hubs. It stimulates innovation from, e.g., energy storage to smart meters.

In the energy sector, there are prerequisites for all three of these trends, which heavily depend on the public policy related to the three "Ds" issue. In our study, the three "Ds" concept was examined to understand the impact of global trends on the need for technologies (technology trends) adapted to achieve the SDGs in the fossil fuel energy sector.

\section{Technology trend of "digital transformation"}

The stage of digital transformation is characterized by the development of technologies, means of telecommunications, high-precision navigation, computing technologies, and robotics. The introduction of digital technologies will provide full automation of most of the processes for the optimization of production cycles. This will lead to increased labor productivity, improved competitiveness of the industry, and reduced numbers of accidents and injuries in factories. The creation of a digital twin technology of underground gas storage facilities will improve safety and energy efficiency. A digital twin is a virtual representation of an object or system that spans its lifecycle that is updated from real-time data and uses simulation, machine learning, and reasoning to help decision-making. It means creating a highly complex virtual model that is the exact counterpart (or twin) of a physical thing. The existing efficiencies of oil and gas fields can be improved by comprehensive analysis of the existing data flow [46].

2. Technology trend of "sustainability"

There is a need to introduce the best available technologies at each technological stage of geological exploration, transportation of hydrocarbons, and the use of energy in order to reduce environmental damage [47]. The introduction of highly efficient, low-emission technologies is a key step towards the implementation of carbon capture and storage technology. Improving the efficiency of coal-fired power plants by just $1 \%$ reduces the $\mathrm{CO}_{2}$ emissions by some $2 \%-3 \%$ [48]. As a result of the rising energy consumption, $\mathrm{CO}_{2}$ emissions increased from $1 \%$ to $1.5 \%$ in 2019 , also due to the global increase in natural gas (NG) consumption [49]. In the Russian Federation, Iraq, Iran, and the United States, more than half of the world's gas is flared [50]. Based on this, there is an obvious need for an integrated approach to the reduction of greenhouse gas emissions. Moreover, it is neccesary to adapt to ever-increasing fluctuations in the consumption of the fossil energy, which will be dictated by renewable energy resources.

3. Technology trend of "import substitution"

In the context of the unstable geopolitical situation, it is necessary to develop our own production. This will reduce the dependence of countries on foreign developments [51]. At the same time, the leading developers of innovative foreign equipment, as a rule, do not sell the most competitive of the fresh technologies of their own production to other countries, thereby artificially strengthening the reliance on supplies of foreign equipment and the technological lag of local companies in different countries.

4. Technology trend of "hard stocks"

The problem of the depletion of current "light oil" reserves has motivated companies to switch to the development of hard-to-recover reserves: shale oil, offshore fields, and highviscosity oil fields. Complicated operating conditions of existing and new fields, the growth of prices for materials, equipment, and electric power lead in the aggregate contributes to increases in the cost of the production of oil. In such conditions, the oil-producing companies can strictly remain competitive through an extensive use of innovative technologies [18].

5. Technology trend of "transport electrification"

Currently, the widespread distribution of electric mobility and the production of storage batteries lead to an increase in demand for new materials and rare earth metals. 
Under the EV30@30 Scenario, electric vehicles (excluding two-wheelers) will account for 30\% (about 43 millions) of all vehicles [52]. Under the scenario described in work of O'Sullivan, the demand for cobalt will increase by 170 kilotons/year; regarding lithium and manganese, it will be 155 kilotons/year, and finally, for grade 1 nickel, 850 kilotons/year are targeted [3]. Such growth of the demand for rare-earth metals leads to increasing the importance of the raw materials sector in electric transport and generates new challenges related to market expansion, security of supply, and environmental control. There is also a growing urgency to extend battery life using the three "Rs": reduce, reuse, and recycle. Leading countries are represented in [53,54].

These global trends strongly influence the technological development in developing countries [55]. In the context of the changing realities of the world and of the global challenges, technology trends should become not only tools for achieving the SDGs but also factors in the qualitative transformation of the energy sector, which are based on the properties summarized in Figure 3.

\section{PROPERTIES OF SUSTAINABLE DEVELOPMENT OF FOSSIL ENERGY}

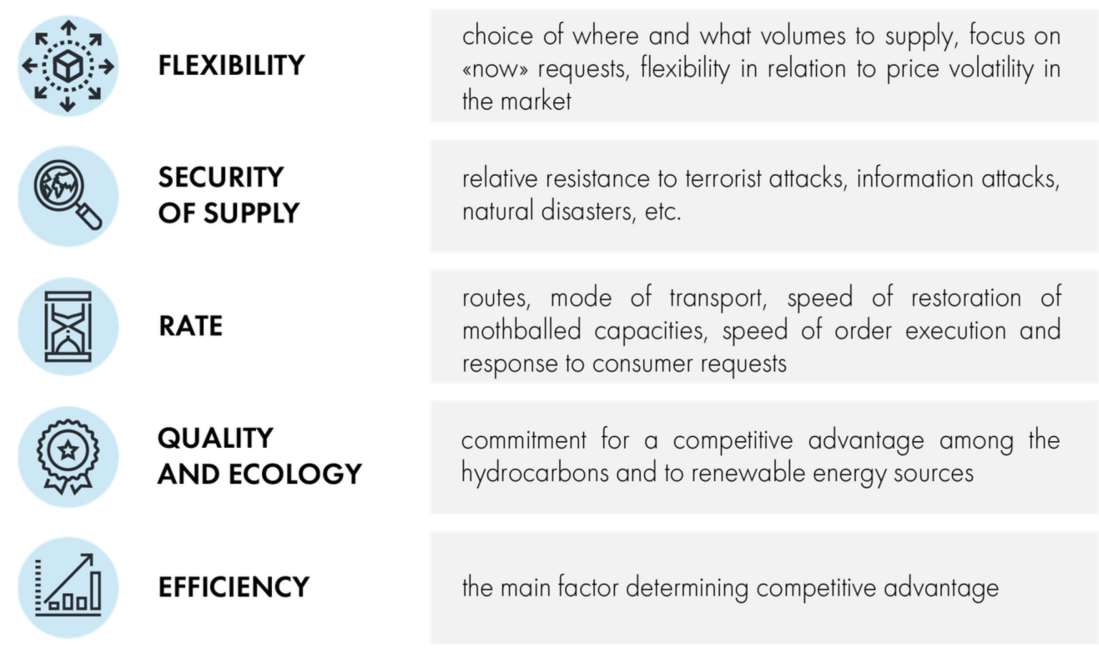

Figure 3. Properties of the sustainable development of fossil energy $[18,56]$.

Fossil energy in developing and transition countries, including the Russian Federation, can strengthen and maintain its position in the global energy sector by changing the approach for taking advantage of it at each stage of production (extraction, storage, transportation, processing, conversion, and conservation) in order to achieve the five properties required for the shifting energy sector in agreement with the prescriptions of the SDGs.

\section{Materials and Methods}

The methodological approach of our study was based on a scenario forecasting approach [25-28,57]. Our scenarios necessarily took into account:

1. Technologies and the directions of their development of primary interest;

2. Analysis of the state and the prospects of the development of the fossil energy;

3. Comprehensive analysis of global risks [28];

4. Factor analysis based on expert assessments resulting from a survey of employees of energy companies and graduates of specialized universities.

In previous studies of the authors of the work, the importance of risk assessment in scenario forecasting based on expert judgments was proven relevant for going further [56,58]. It proposed use of the Delphi survey $[56,59,60]$. The different method steps of this research through the Delphi process are presented in Figure 4. 


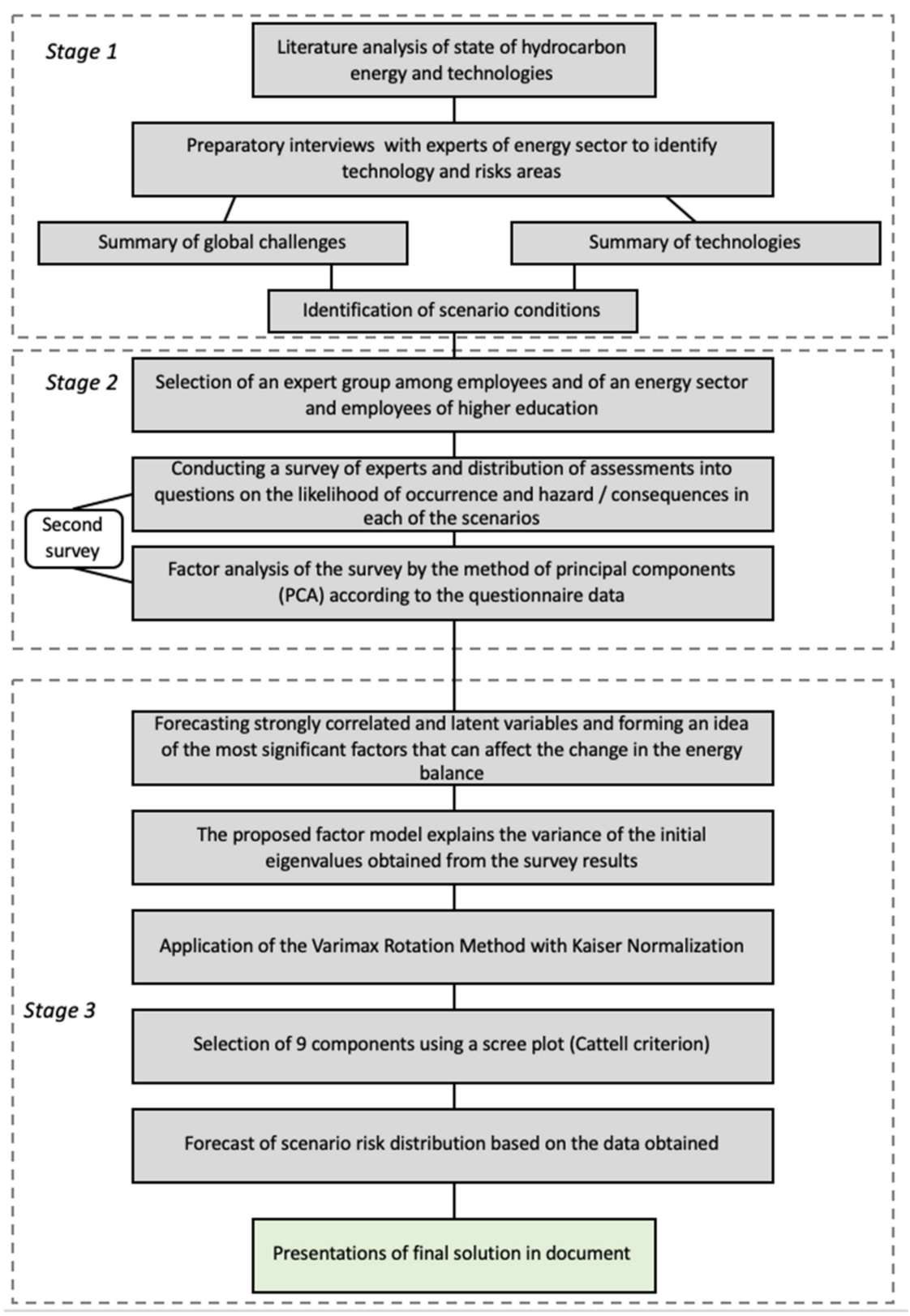

Figure 4. Steps of the research.

This method is widely used for planning scenarios in the energy sector. It involves the generalization of all individual expert assessments regarding one specific situation.

Herein, it was organized as follows: in the first stage of the study, a small working group of experts from the field of professional workers and teachers of specialized universities was assembled. Then, the questionnaire was constructed by this working group based on the brainstorming method effectively applied in the previous study [56]. At the second stage of the study, the group was expanded, and the expert survey was conducted. The answers to the questions were generalized in order to offer a global vision. An expert group was composed of 70 experts of the appropriate research field. Based on the results of this survey, key risks for sustainable development of the energy sector could be identified. At the third stage, a factor model and final solutions were formed.

Before the formation of scenarios, 7 types of risks were identified in political, sociocultural, economic, legal, technology, environmental, and commercial spheres [28,61]. At first, the risks were analyzed, and their degrees of influence on the volumes of production 
of fossil fuel for a given period (2020) were established. They are compactly presented in Table 2.

Table 2. Global risks for fossil energy [45,52-55,62].

\begin{tabular}{|c|c|c|c|c|c|}
\hline Types of the Risk & & The Name of the Risk & $\begin{array}{c}\text { Type of } \\
\text { Influence }\end{array}$ & $\begin{array}{l}\text { Event Probability: } \\
\text { High }(>60 \%), \\
\text { Medium }(20-60 \%), \\
\text { Low }(<20 \%)\end{array}$ & $\begin{array}{c}\text { Degree of } \\
\text { Influence: Weak } \\
(<0.2) \text {, Medium } \\
(0.2-0.6) \text {, Strong } \\
(>0.6)\end{array}$ \\
\hline \multirow{3}{*}{ R1. Political } & $\mathrm{P} 1$ & Sanctions & Indirect & High & 0.5 \\
\hline & $\mathrm{P} 2$ & Nationalization of the industry & Direct & Medium & 0.8 \\
\hline & P3 & Weakening the system of globalization & Direct & High & 0.7 \\
\hline \multirow{5}{*}{ R2. Sociocultural } & $\mathrm{S} 4$ & Shortage of human resources & Direct & High & 0.9 \\
\hline & S5 & $\begin{array}{l}\text { Insufficient popularization of energy-saving } \\
\text { production and consumption }\end{array}$ & Direct & High & 0.8 \\
\hline & S6 & $\begin{array}{c}\text { Emergencies (spread of epidemics, } \\
\text { viruses, etc.) }\end{array}$ & Indirect & High & 0.95 \\
\hline & S7 & Growing and aging of the population & Indirect & Medium & 0.8 \\
\hline & S8 & Crisis of city-forming coal enterprises & Direct & Medium & 0.7 \\
\hline \multirow{4}{*}{ R3. Economic } & E9 & The volatility of the prices of the energy & Direct & High & 0.9 \\
\hline & E10 & Price dumping & Direct & Medium & 0.6 \\
\hline & E11 & Power consumption & Direct & High & 0.9 \\
\hline & E12 & Financial crises & Direct & High & 0.9 \\
\hline \multirow{2}{*}{ R4. Legal } & L13 & Changes in tax legislation & Indirect & Medium & 0.7 \\
\hline & L14 & Environmental regulation & Direct & High & 0.8 \\
\hline \multirow{3}{*}{ R5. Technological } & $\mathrm{T} 15$ & Lack of developed energy infrastructure & Direct & High & 0.8 \\
\hline & $\mathrm{T} 16$ & $\begin{array}{c}\text { Deterioration of the quality characteristics of } \\
\text { hydrocarbons }\end{array}$ & Direct & High & 0.9 \\
\hline & $\mathrm{T} 17$ & Growth of hard-to-recover reserves & Direct & High & 0.9 \\
\hline \multirow{2}{*}{ R6. Environmental } & E18 & Growth in carbon footprint & Direct & High & 0.8 \\
\hline & E19 & Environmental pollution & Direct & High & 0.9 \\
\hline \multirow{2}{*}{ R7. Commercial } & K20 & Access to loans & Direct & High & 0.8 \\
\hline & K21 & Investments & Direct & High & 0.8 \\
\hline
\end{tabular}

The creation of fossil energy scenarios was based on a comprehensive analysis of global risks, since many factors accompanying crisis phenomena can influence decision-making and program implementation.

In order to carry out a subsequent risk assessment $[63,64]$ depending on the likelihood of occurrence in each of the scenarios on the danger of each risk and taking into account the consequences and the time required to eliminate them, a questionnaire was composed. The questions of interest for us here are highlighted in Table 3.

In addition, the answers to questions R1-7 were weighted on the scale of the probability of risk occurrence (unlikely, medium, very likely) and of the degree of their influence (does not affect, has an average effect, has a strong effect). Each of the options for answers, depending on the question, referred to one of the energy development scenarios. Accordingly, depending on how many respondents chose a given option of answer, the value of the probability of this risk occurrence in a particular scenario was formed. 
Table 3. The questions of the questionnaire.

Type of the Risk Questions

1. What is the likelihood that sanctions related to access to foreign technology will be imposed in the next $10-15$ years?

2. What impact do the sanctions have on the growth of hydrocarbon consumption?

3. What is the likelihood of stagnation in the development of the oil and gas sector due to the nationalization of the industry?

4. How strong is the impact of industry nationalization on the development of the fossil fuel sector of the Russian energy sector?

5. What will be the share of operating expenses in the oil market until 2035?

1. What will be the shortage of human resources in the energy sector until 2035?

2. How does the lag of the education system and production trends affect the competencies of university graduates?

3. How is the growing demand for energy related to the popularization of energy-efficient production and consumption?

4. What is the impact of the spread of epidemics. viruses. etc. on long-term plans for environmental programs?

5. How does the spread of epidemics, viruses, etc. affect the transition to electric vehicles?

6. What is the impact of the spread of epidemics, viruses, etc. on the transition to renewable energy sources?

7. What is the probability of an increase in the share of the working-age population by 2035 ?

8. What is the probability that coal exports to the Asia-Pacific region will decrease by 2035 ?

9. How does the coal industry's slow improvement in environmental friendliness and efficiency affect job losses in Russia's single-industry towns?

1. Will the trend of outstripping supply in the hydrocarbon market over demand continue until 2035?

2. What is the impact of energy price volatility on the capital and operating costs ofmajor energy producers?

3. How does the use of energy price dumping affect the geopolitical situation in the world?

4. Will global oil demand peak by 2035 ?

5 . How will the demand for oil change if primary energy consumption continues to increase?

6. How will epidemics, viruses, etc. affect investment in large long-term projects with high maintenance costs?

7. Should the government be expected to invest in short- and long-term projects through government economic incentives/programs?

\section{Should we expect state support for new petrochemical projects in Russia?}

2. Should we expect new programs/tax incentives to stimulate domestic manufacturers of equipment and technology?

4. What is the relationship between publicly available greenhouse gas emissions reporting by large industrial companies and the investment attractiveness of these companies?

1. What effect does the deterioration of the energy infrastructure have on the speed of adoption of information and digital technologies?

2. How does the deterioration of the energy infrastructure affect electricity tariffs?

3. What impact will the formation of petrochemical clusters have on the development of the petrochemical market?

4. What new risks will emerge due to the growth of hydrocarbon production costs?

1. How does the need to reduce the carbon footprint affect the growth of LNG market share?

2. How do possible import duties for companies with high carbon footprints affect Russian exports?

3. Should we expect innovative state programs for industrial waste disposal before 2035 ?

1. Will the impact of the coronavirus affect the deterioration of the quality of credit portfolios of large industrial exporting companies in Russia?

Based on the information collected, a factor analysis was finally conducted using the principal component method for the purpose of determining strongly correlated and latent variables to form an idea of the most significant factors that can affect the development of 
the fossil energy in the Russian Federation and in the scale of the world. The risks were used as criteria, and they were grouped into 9 components. These 9 components were identified using the Varimax rotation method with Kaiser normalization $[65,66]$ based on the graph of scree and the viability of theories, each of which was attributed a name. The scree criterion was to find the point where the decay of the eigenvalues slowed down the most. This criterion was proposed by Kaiser (1960) and is probably the most widely used in statistics [66]. The results of the risk analysis were combined for all three scenarios together with the factor analysis performed. The resulting generalized factorial model of scenario risks provided prerequisites for understanding the possible directions of formation of support programs. Thus, programs, according to the generalized model, could have a positive impact on the economy at any scenario development. This is important, as indicators of development of scenarios are not always available. Thus, at the given stage of development of a certain scenario path, the missed preventive actions led to the increase in volume of necessary countermeasures and support.

\subsection{Analysis of Global Risks}

In addition to the issues of the volatility of prices for energy resources, and in accordance with the geopolitical situation, there are several other risks and constraints due to the concentration of technological development in industry, limited to traditional basic technologies. This leads to the need to modernize the energy sector to achieve sustainable development of fossil energy.

During our analysis of the collected data, the predicted states of the energy sector were studied while accounting for the impact of each of the 21 risks from Table 2 in the contexts of negative, positive, and conservative scenarios, respectively. The results of the risk impact analysis are presented in Table 4.

Table 4. Forecasted states of fossil energy with the account of the influence of risks $[45,52-55,61,67]$.

\begin{tabular}{|c|c|c|c|}
\hline & Negative & Positive & Conservative \\
\hline P1 & $\begin{array}{l}\text { 1. Decrease in crude oil production by } \\
4 \% \text { (from } 83 \text { million barrels per day to } \\
80 \text { million barrels per day) } \\
\text { 2. Lack of access to foreign } \\
\text { technologies for the implementation } \\
\text { of new projects } \\
\text { 3. Lack of technological capabilities to } \\
\text { stimulate production at existing fields }\end{array}$ & $\begin{array}{l}\text { 1. Adaptation to new conditions } \\
\text { 2. Search for new partners (projected } \\
\text { growth of crude oil production of } 2 \% \text { ) } \\
\text { (from } 83 \text { million barrel/day to } 84.66 \\
\text { million barrel/day) } \\
\text { 3. Development of our own } \\
\text { technologies }\end{array}$ & $\begin{array}{l}\text { 1. Interruptions in the supply of } \\
\text { energy resources } \\
\text { 2. Maintaining the existing } \\
\text { production volumes at the expense of } \\
\text { already prepared deposits } \\
\text { 3. Possible decrease in crude oil } \\
\text { production by } 2 \% \text { to } 81.34 \text { million } \\
\text { barrels per day }\end{array}$ \\
\hline $\mathrm{P} 2$ & $\begin{array}{l}\text { 1. Imbalance in ownership ( } 100 \% \text { is } \\
\text { either in private hands or in the } \\
\text { hands of the state) } \\
\text { 2. Adoption of subjective decisions } \\
\text { aimed at meeting the needs of an } \\
\text { exclusively specific copyright holder } \\
\text { 3. Stagnation or regression of the oil } \\
\text { and gas sector is likely in both } \\
\text { technological and economic terms }\end{array}$ & $\begin{array}{l}\text { 1. Balance of ownership ( } 45 \% \text { in the } \\
\text { hands of the state) } \\
\text { 2. Most decisions are made by private } \\
\text { companies under partial control of } \\
\text { the state. } \\
\text { 3. High rate of development of the } \\
\text { NG industry }\end{array}$ & $\begin{array}{l}\text { 1. Minor imbalance in ownership } \\
(60 \% \text { in the hands of the state) } \\
2 . \text { Most of the decisions are made by } \\
\text { private companies under strict partial } \\
\text { control of the state. } \\
\text { 3. Insignificant losses in economic } \\
\text { and technological development of the } \\
\text { sector }\end{array}$ \\
\hline P3 & $\begin{array}{l}\text { 1. Decline in the share of OPEC: less } \\
\text { than } 45 \% \text { in the market } \\
\text { 2. Market volatility fluctuations in oil } \\
\text { prices (from negative values to USD } \\
5.00 / \text { barrel) and gas (less than USD } \\
\text { 1.6/million BTU) } \\
\text { 3. Price dumping-subsidized oil } \\
\text { consumption }\end{array}$ & $\begin{array}{l}\text { 1. OPEC share up to } 65 \% \text { in the } \\
\text { market } \\
\text { 2. Consolidation of interests of } \\
\text { companies in the fuel and energy } \\
\text { complex } \\
\text { 3. Containment of oil prices at USD } \\
45.00 / \text { barrel }\end{array}$ & $\begin{array}{l}\text { 1. OPEC share up to } 60 \% \text { in the } \\
\text { market } \\
\text { 2. More new players enter the market } \\
\text { (USA, Brazil, Canada, Norway) } \\
\text { 3. Saturation of the market with } \\
\text { cheap energy sources (shale oil, } \\
\text { Canadian bituminous oil) } \\
\text { 4. Containment of oil prices at USD } \\
\text { 25.00-35.00 per barrel }\end{array}$ \\
\hline
\end{tabular}


Table 4. Cont.

\begin{tabular}{ll}
\hline \multicolumn{1}{c}{ Negative } \\
\hline \\
1. Lagging education system \\
2. Decrease in labor productivity \\
3. The disappearance of old \\
professions (up to 60 specialties) \\
4. Retraining of $10 \%$ of company \\
employees (up to $31 \%$ of a thousand \\
people leave for a new job due to \\
their unwillingness to change)
\end{tabular}

1. Growth of energy losses up to $30 \%$ due to the lack of a modern system of organizational and legal management mechanism

S5 2. Decrease in labor productivity 3. Growth of injury risk at production facilities4. Growth of demand for energy resources (unfounded consumption)

\section{Sharp decline in demand for} hydrocarbons by $20 \%$

2. An abnormal drop in oil prices to negative values for the first time in 30 years

S6 3. Serious threat to long-term action on climate change

4. A sharp decline in demand for renewable energy5. Suspension of the life of megalopolises; conservation of production processes

1. Decrease in fertility rates of 2.5 children per woman in 2019 to 1.5 in 2050.

2. The able-bodied population will be less than $78 \%$ by 2050

3. Regional and transcontinental migration $4.5 \%$ of skilled engineers are going to retire in the next 10 years

1. Reduction of jobs in more than 30 monotowns with a population of up to 110 thousand people

2. Falling demand and price volatility with a decrease in coal exports to Europe and China (50\% of the 2019 export volume)

3. Restrictions on exports to the countries of the Asia-Pacific region
1. Retraining of more than $60 \%$ of employees of oil and gas companies 2. Cooperation of enterprises and universities

3. Wide information availability 4. Labor productivity growth5. The disappearance of up to $200 \mathrm{old}$ professions. but the emergence of new professions

1. Reducing dependence on imported equipment and technologies

2. Growth of investments in energy saving by $2 \%$ of GRP annually

3. Progress in introducing energy-efficient thinking into society 4. Decrease in demand for energy resources

1. Temporary reduction in global carbon dioxide emissions (250 million tons $\mathrm{CO}_{2}, 18 \%$ below normal levels)

2. Reducing the load on the transport infrastructure

3. Introduction of government packages of economic stimulus that will invest in clean energy technologies and contain the economic crisis

4. Maintaining demand for renewable energy at the level of 2020

1. Steady growth in the global standard of living

2. Growth of the working-age population up to $85 \%$

3. Growth in average world life expectancy by about $15 \%$

4. Growth of potential for implementation and mastering of new technologies

1. Growth of exports to the Asia-Pacific region by an average of $0.65 \%$ /year $(13 \%$ by 2040$)$

2. Development of related industries (coal chemistry, mechanical engineering, metallurgy) 3. The volume of investments by 2035 will amount to 2.5-3.5 trillion rubles

4. Tax revenues will grow by 2.6 times
Conservative

1. Increasing the attractiveness of jobs due to the introduction of a center for additional professional education 2. Retraining up to $35 \%$ of employees 3. Growth in labor productivity with a significant increase in operating expenses for the production of raw materials

1. Stagnation of the energy intensity of GDP (over the past 10 years, the energy intensity of the RF GDP decreased by only $9 \%$. In the last 4 years, the energy intensity of GDP did not decrease)

2. Development of systems for stimulating personnel to efficient consumption based on digital technologies

1. Reducing the demand for renewable energy up to $55 \%$ 2. Provisional focus on short-term economic incentives instead of long-term clean technologies 3. The economic crisis slows down the growth rate

4. Sustainability of the gas industry compared to other fuels

1. A slight decrease in fertility from 2.5 children per woman in 2019 to 2.2 in 2050

2. Growth of the working-age population up to $80 \%$

3. Growth in average life expectancy by $10 \%$ (77 years in the world on average)

1. Growth of exports to the Asia-Pacific region by an average of $0.4 \%$ /year ( $8 \%$ by 2040 )

2. Modernization of coal generation facilities

3. Raising the level of industrial safety and improving working conditions, creating digital competence centers 4. Improving the environmental friendliness and efficiency of the coal industry 
Table 4. Cont.

\begin{tabular}{ll}
\hline \multicolumn{1}{c}{ Negative } & \multicolumn{1}{c}{ Positive } \\
\hline $\begin{array}{l}\text { 1. Decrease in momentary values of } \\
\text { oil prices below USD 5.00/barrel }\end{array}$ & $\begin{array}{l}\text { 1. Maintaining the price at USD } \\
\text { 2. Decrease in gas price below USD } \\
\text { 1.6/million BTU }\end{array}$ \\
$\begin{array}{ll}\text { 3. Decrease in world demand for oil } \\
\text { by 10-11 million barrels per day with } \\
\text { by 10-11 million barrels per day with } \\
\text { an increase in supply by 5-6 million } \\
\text { barrels per day }\end{array}$ & $\begin{array}{l}\text { a mutual decrease in supply by 5-6 } \\
\text { by no more than 10\% }\end{array}$ \\
$\begin{array}{l}\text { 4. Decrease in the average annual rate } \\
\text { of world GDP growth by 2.4\% }\end{array}$ & $\begin{array}{l}\text { 3. Decrease in the average annual rate } \\
\text { of world GDP growth by 0.5\% }\end{array}$ \\
$\begin{array}{l}\text { 5. Capital and operating expenses are } \\
\text { 6-7 times higher than oil prices for } \\
\text { the largest producers }\end{array}$ & $\begin{array}{l}\text { 4. Costs for capital and operating } \\
\text { expens are commensurate with oil } \\
\text { prices for the largest producers }\end{array}$ \\
\hline
\end{tabular}

1. Competitors of the Russian

Federation and the United States offer oil at a price of about USD 25.00 per barrel, which is a huge discount compared to the price of other producers

E10 2. Increase in oil production by $25 \%$ (by 12.3 million barrels per day) by Saudi Arabia-increasing competition and ensuring artificial monopolization of oil markets 3. Loss of exports in Saudi Arabia5. Crowding out unsubsidized energy sources

1. Primary energy consumption will increase by $30 \%$ by 2040

2. The growth in demand for oil will be $17 \%$ and will reach $4.9-5$ billion tons by 2040

3. Natural gas consumption will increase by $40 \%-55 \%$ by 2040 .

4. Demand for electricity will increase by $60 \%$ by 2040

5 . Decrease in demand for renewable energy sources. The share of the new generation will increase by 1.5 times. 6 . Demand for coal will peak until 2025

1. Decrease in the average annual growth rate of world GDP by $2.4 \%$ 2. Hyperinflation (growth rate over $50 \%$ )

3. Mothballing production at large fields with expensive maintenance 4. Reduced investment in short-term and long-term projects
1. Maintaining a unified policy of 2. Reducing the sharp increase in oil production to $3 \% /$ day in order to maintain anti-crisis oil prices 3. Without subsidies, oil and gas exporters will still have a comparative advantage in the energy sector since a low-cost base can provide a consistently low domestic price

1. Consumption of primary energy will increase by no more than $10 \%$ by 2040

2. Decrease in demand for oil to $20 \%$ which will reach 3.2 billion tons. by 2040

3 . Renewable energy generation will increase 5-6 times by 2040.

4. Energy strategy of the Russian Federation forecasts LNG production up to 120-140 million tons in 2035 price regulation of oil prices

1. Decrease in oil prices below USD 22.00/barrel

2. Supply exceeds demand by no more than $25 \%$

3. Economic and industrial imbalance in the short term3. Decrease in average annual rates of world GDP growth from $0.5 \%$ to $2.5 \%$ 4. Costs for capital and operating expenses are 2-3 times higher than oil prices for the largest producers

1. Sharp reduction of oil production increase to $7 \%$ /day to support anti-crisis oil prices

2. The impact of the pricing reform on energy consumers can be significantly mitigated if the reform is combined with enhanced energy efficiency measures with significant financial and environmental benefits 3. Decrease in the price for the business of largest oil companies in the Russian Federation: USD 20.00/barrel

1. Consumption of primary energy will increase by no more than $25 \%$ by 2040

2. Growth in electricity consumption by 2035 by $1.18-1.25$ times to 1380 billion $\mathrm{kWh}$

3. Generation of renewable energy sources will increase 2.5 times

4. Growth in natural gas consumption: the share of which in world energy consumption in the period until 2040 will grow from 22\% to $27 \%$

1. Increase in the average annual growth rate of world GDP by $3.3 \%$ 2. Moderate inflation $(8 \%-10 \%)$

3. Maintaining investments in short-term and long-term projects at the expense of the state economic incentives
1. Decrease in the average annual growth rate of world GDP from $0.5 \%$ to $2.5 \%$

2. Moderate inflation (10\%-15\%)

3. Reduced investment in long-term projects 
Table 4. Cont.

\begin{tabular}{|c|c|c|c|}
\hline & Negative & Positive & Conservative \\
\hline L13 & $\begin{array}{l}\text { 1. Tightening the tax regime for } \\
\text { mature fields } \\
\text { 2. Introduction of value-added taxes } \\
\text { (VAT), which depends on the } \\
\text { financial result of the project. If it } \\
\text { proves its viability, it will be } \\
\text { introduced to a greater number of } \\
\text { mature fields }\end{array}$ & $\begin{array}{l}\text { 1. Providing loans at low interest } \\
\text { rates to oil and gas producers who } \\
\text { face declining oil prices due to the } \\
\text { epidemiological situation } \\
2 \text {. Target system of tax incentives in } \\
\text { the form of VAT refunds }(5 \%-13 \%) \text {, } \\
\text { tax holidays, customs subsidies, and } \\
\text { negative excise taxes on raw materials } \\
\text { 3. Subsidizing the procurement of } \\
\text { new equipment and technologies. } \\
\text { support for investment projects }\end{array}$ & $\begin{array}{l}\text { 1. State support for new projects in } \\
\text { the petrochemical industry. } \\
\text { incentives for equipment and } \\
\text { technology manufacturers. incentives } \\
\text { for large-scale products } \\
\text { 2. Tax incentives for new fields with } \\
\text { high water cuts }\end{array}$ \\
\hline L14 & $\begin{array}{l}\text { 1. As a result of the lack of clear } \\
\text { values of MPC (maximum } \\
\text { permissible concentration) of oil } \\
\text { products in the soil, the process of } \\
\text { taking corrective measures to reclaim } \\
\text { damaged areas is complicated } \\
\text { 2. Tightening the decarbonization } \\
\text { policy forcibly reducing greenhouse } \\
\text { gas emissions }\end{array}$ & $\begin{array}{l}\text { 1. Monitoring and reporting of large } \\
\text { industrial and energy enterprises } \\
\text { with an annual emission of } \\
\text { greenhouse gases of } 150 \text { thousand } \\
\text { tons in terms of carbon dioxide }\left(\mathrm{CO}_{2}\right. \\
\text { equivalent) and more } \\
2 \text {. Economic incentives for the } \\
\text { utilization of associated petroleum } \\
\text { gas by gradually increasing fees for } \\
\text { negative impact on the environment }\end{array}$ & $\begin{array}{l}\text { 1. Decarbonization policy by keeping } \\
\text { the growth of the global average } \\
\text { temperature within } 1.5-2{ }^{\circ} \mathrm{C} \\
\text { 2. Between } 2020 \text { and } 2025 \text {, state } \\
\text { regulation of emissions will be } \\
\text { implemented for greenhouse gases } \\
\text { 3. Conditions were created to } \\
\text { stimulate the implementation of } \\
\text { projects aimed at reducing } \\
\text { greenhouse gas emissions and their } \\
\text { absorption }\end{array}$ \\
\hline
\end{tabular}

\section{Depreciation of energy} infrastructure will approach $75 \%$ by 2040

2. The required investments exceed the existing ones by 42 thousand billion rubles $(21 \%)$

$\mathrm{T} 15$

3. Decreased reliability of the hydrocarbon transportation process 4. In the Russian Federation, up to 19,000 accidents annually due to the use of outdated low-efficiency equipment

\section{Depreciation of the energy}

infrastructure can reach $35 \%$

2. The required investments exceed the existing ones by 13 trillion rubles (7\%).

3. Reduction of the number of accidents when using worn-out equipment by $2-3$ times

4. Implementation of virtual power plants: long-term tariff agreements The launch of training for new personnel ready to work in the digital power grid complex
1. Decrease in product quality

2. Depreciation of production assets-the risk of the impossibility of updating (a large share of technological imports) 3. Low bandwidth of hydrocarbon transportation facilities
1. Formation of petrochemical clusters (from extraction to the production of end products with high added value)

2. Development of the ethylene and olefins market (creation of transport infrastructure-ethylene pipelines and railway transport-infrastructure mortgage)

3. Using cycling technology in the gas market
1. Depreciation of the energy infrastructure can reach $48 \%$ 2 . The required investments exceed the existing ones by 28 trillion rubles $(17 \%)$

3. The tariff burden will continue to increase. taking into account inflation by $12 \%$ annually

1. Increasing the depth of oil refining (up to $90 \%$ ). Increasing the yield of light oil products (up to $74 \%$ ) 2. Completion of the program of modernization of oil refineries 3 . Reducing operating costs at refineries through the use of digital technologies

4. Expansion of production and consumption of NGV fuel 5. Development of the unified gas Supply system, construction of auxiliary LNG infrastructure 6. Increase in LNG production by 5 times or more

7. Creation of LNG clusters8. Slight growth in demand for methanol up to $2 \%$ per year 
Table 4. Cont.

\begin{tabular}{llll}
\hline \multicolumn{1}{c}{ Negative } & \multicolumn{1}{c}{ Positive } & \multicolumn{1}{c}{ Conservative } \\
\hline & $\begin{array}{l}\text { 1. Increase in the cost of hydrocarbon } \\
\text { production }\end{array}$ & $\begin{array}{l}\text { 1. Growth of the latest production } \\
\text { technologies (Russian reserves of } \\
\text { 2. Significant increase in the costs of } \\
\text { exploration and production }\end{array}$ & $\begin{array}{l}\text { 1. The peak of production of } \\
\text { traditional light oils will be reached } \\
\text { estimated at 5-7 billion tons) }\end{array}$ \\
$\begin{array}{l}\text { 3. Increased risks associated with the } \\
\text { need of additional capital } \\
\text { investments }\end{array}$ & $\begin{array}{l}\text { 2. In-depth development of existing } \\
\text { traditional oil fields using production } \\
\text { intensification methods }\end{array}$ & $\begin{array}{l}\text { 2. Stagnation of technologies for the } \\
\text { production of heavy and bituminous } \\
\text { oil with huge reserves }\end{array}$
\end{tabular}

1. Reducing the intensity of carbon dioxide emissions due to energy efficiency and an increase in the share of renewable energy sources

1. By 2030, the number of carbon dioxide emissions in the world can reach 40 gigatons

2. Global warming by $3.5^{\circ} \mathrm{C}$

3. In the Russian Federation, the growth of greenhouse gas emissions from 1.6 billion tons of $\mathrm{CO}_{2}$ eq. to 2.4 billion tons of $\mathrm{CO}_{2}$ eq. by 2030

1. Infiltration of wastewater up to $40 \%$ of the oil that got into reservoirs settles to the bottom in the form of bottom sediments

E19

2. Significant decline in biodiversity and, more importantly, soil fertility 3. Forest fires4. Increasing the sorption capacity of coal
2. Growth of the share of LNG as an alternative to fuel oil by $5 \%$ per year by 2035 (reduction of $\mathrm{SO}_{\mathrm{x}}, \mathrm{NO}_{\mathrm{x}}$, and particulate matter emissions)

3. In the Russian Federation, the increase in the intensity of emission growth from 1.6 billion tons of $\mathrm{CO}_{2}$ eq. to 1.9 billion tons of $\mathrm{CO}_{2}$ eq. by 2030 and a decrease to 1.6 billion $t$ eq. by 2050

1. Introduction of energy-saving technologies, reduction of energy losses

2. Increasing the volume of waste processing, reclamation of the largest landfills, utilization of methane 3. Production and use of products with high energy efficiency class 4. Protection of forests from fires and pests, reduction of clear felling
1. Expansion in the market of the gas and the LNG continues and LNG demand is expected to increase by $3.6 \%$ per annum until 2035

2. In the Russian Federation, the growth of greenhouse gas emissions from 1.6 billion $\mathrm{g}$ of $\mathrm{CO}_{2}$ eq. to 2.07 billion tons of $\mathrm{CO}_{2}$ eq. $\mathrm{CO}_{2}$ by 2030

1. Prevention of accidents and their consequences

2. Filtration of contaminated wastewater at the stage of drilling operations

3. Reclamation of contaminated land in the northern regions4. Introduction of modern technologies of oil production
1. In 2020, a slowdown in consumer demand growth is expected (to $0.6 \%$ after $1.0 \%$

in 2019) driven by a slowdown in consumer credit growth

2. Against the backdrop of the COVID-19 pandemic, the banking sector is facing a deterioration in the quality of loan portfolios of both corporate and retail borrowers
1. Suspension of the key rate cut cycle

2. Development of lending within the framework of state programs, rates for which are in the range of $2 \%-5 \%$
1. A significant reduction in foreign currency lending $(86.2 \%$ of total capital at the beginning of 2020 versus $113 \%$ as of September 2008) 2. Slowdown in the growth rate of the portfolio of consumer loans.3. Rapid decline in the key interest rate

\begin{tabular}{ll}
$\begin{array}{l}\text { 1. By 2024, an increase in investment } \\
\text { by } 7.5 \text { trillion rubles. That is, in fact, } \\
\text { an increase in the volume of } 50 \% \\
\text { compared to the current situation }\end{array}$ & $\begin{array}{l}\text { 1. A break in the activity, but key } \\
\text { players will continue their investment } \\
\text { activity, focusing on "safe" markets }\end{array}$ \\
$\begin{array}{l}\text { 2. Implementation of large } \\
\text { investment projects at the expense of }\end{array}$ & $\begin{array}{l}\text { exchange rates during the second and } \\
\text { third quarters of 2020, investment } \\
\text { activity will also be affected by the }\end{array}$ \\
$\begin{array}{l}\text { instruments (public-private } \\
\text { partnership, territories of advanced } \\
\text { inabial and economic development, } \\
\text { special investment contracts, }\end{array}$ & $\begin{array}{l}\text { 3. Markets that are dependent on } \\
\text { foreign capital may face a decline in } \\
\text { investment activity }\end{array}$ \\
\hline
\end{tabular}

1. Investment in fixed assets can be reduced by $5 \%-8 \%$
Based on the analyzed risks, three scenarios for the development of the global energy sector were developed. These scenarios can become the basis for strategic planning in the formation of development programs. 


\subsection{Description of the Scenarios}

Three contrasting scenarios, \#StayHome, \#StayAlone, and \#StayEffective, for the development of fossil energy, all based on comprehensive analysis of global risks by expert survey and factor analysis, were developed.

\subsubsection{Negative Scenario: \#StayHome}

This scenario is characterized by the following features:

- Maintaining isolation of certain groups of citizens, businesses, and countries;

- Reducing of the consumption of energy, goods, and services to reach a minimum in 2022-2023 in the perspective of maintaining it at a low level until the end of the horizon of our forecasting;

- Growing unemployment;

- High volatility of energy prices;

- Outflow of investment;

- Accelerated deterioration of the infrastructure;

- Deterioration of the environmental situation;

- $\quad$ Risk of energy hunger as well as water and food shortages for certain categories of countries;

- Growth of social tensions in energy-poor countries and countries with a significant foreign trade deficit;

- $\quad$ Reduction of global trade in goods and services in physical and monetary terms;

- Reorientation of products to domestic markets;

- Acceleration of imported substitution.

\subsubsection{Moderate Scenario: \#StayAlone}

This scenario is characterized by the following features:

- Partial restoration of chains of international supply of goods, energy, and materials and instability in the supply of minerals and energy;

- $\quad$ Resumption of the development of unprofitable deposits;

- Investment gap in the infrastructure remains;

- Investments in renewable energy;

- Growing need for qualified personnel;

- $\quad$ Return of the global energy consumption to the previous level;

- Continued deterioration of the environmental situation;

- Increased investment in research, equipment, and personnel for the energy sector.

\subsubsection{Positive Scenario: \#StayEffective}

This scenario is characterized by the following features:

- Complete restoration of temporarily destroyed global supply chains of energy, materials, and goods to reduce costs and to exclude political influence.

- Creation of prerequisites for sustainable development of the global energy infrastructure through international planning and financing;

- Implementation of digital technologies in all life cycles of hydrocarbons, restraining the growth of their consumption;

- Launch of a reliable international system for tracing the origin and for the replenishment of energy and resources, confirming the level of efficiency of the supplied energy and goods and their carbon-free nature.

\subsection{Analysis of the Expert Survey}

The questionnaire was compiled on the basis of the conducted analysis of risks. It was conducted during the period ranging from winter 2019 up to autumn 2020 among 70 respondents from employees of fuel and energy companies (57\%) and employees with the highest level of education working in specialized universities (43\%). The first set 
included: employees of power grid companies (42\%), oil and gas companies (29\%), and coal companies (29\%). The options of answers reflect the likelihood of the risks occurring (unlikely, medium, very likely) or the degree of their impact (does not affect, has an average effect, has a strong effect) on the results.

The responses of these experts were analyzed and broken down for each of the three scenarios, which made it possible to identify which risks are most expected and the degree of danger (with subsequent elimination of the consequences) and to determine the time required to eliminate risks or consequences (shown on the graphs by the size of the circles) for each scenario (Figure 5).
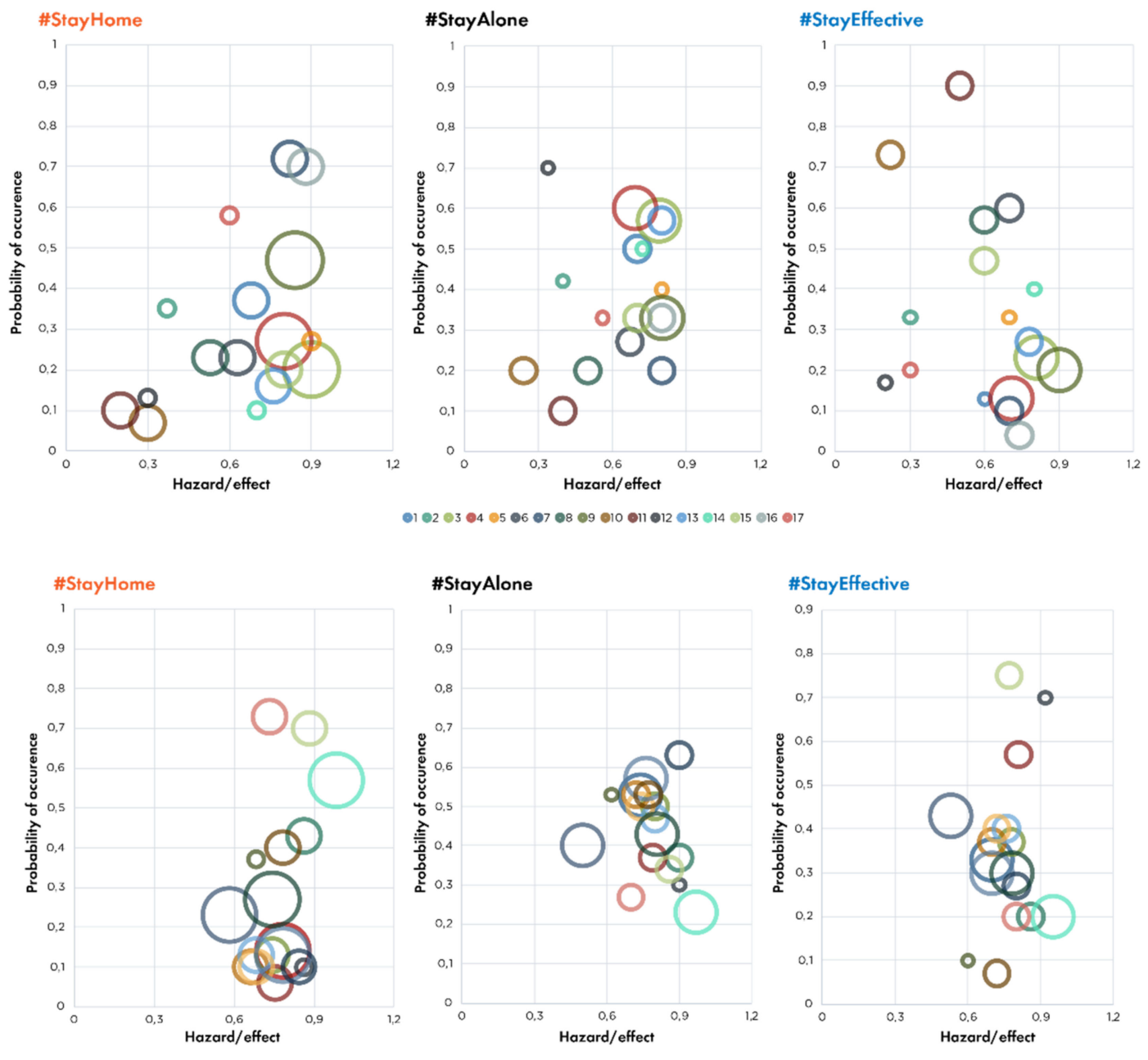

Figure 5. Risk assessment for three scenarios: \#StayHome, \#StayAlone, \#StayEffective.

\section{Results and Discussions}

Based on the data obtained during the survey, the risks were grouped into nine components. Each risk in the three scenarios was assessed in terms of two criteria: the probability of occurrence and the danger of its consequences. This is reflected in the figure as a set of six circles. A comprehensive reading of the figure requires, as a prerequisite, the mastery of a specific grammar based on the rules defined here and below. On the generalized axis, three scenarios are placed for each risk. The time required to eliminate the risk or its consequences is given by the third parameter. This third parameter is the diameter of the circle. The smallest diameter is the elimination period of 1 to 5 years, the average diameter is 5-10 years, and the largest diameter is 10-15 years or more. In case there are three or more circles of medium and large diameter along one axis between 0.6 to 
1 , this is highlighted in orange. Consequently, these risks manifest themselves regardless of the scenario, and this requires immediate preventive measures to reduce the risk of their development and consequences. The components from one to four of the generalized factor model of scenario risks are presented in Figure 6.



Figure 6. The generalized factorial model of scenario risks (components one to four) [56].

Component 1-"efficient energy": In any of the three scenarios, the demand for oil will decline; there is a high probability of a decline in coal exports, which may have a significant impact on export revenues. The correlation with the development of the market of liquefied natural gas (LNG) and the popularization of energy-saving emphasizes the need for a technological development as well as investments in the direction of a popularization of the energy efficiency.

Component 2-"high cost of production": The risk of nationalization of the industry has the greatest weight. It will be accompanied by an increase in the cost of production of fossil fuel. In any of the three scenarios, it creates a threat of stagnation in the development of the oil and gas sector, even though new disease clusters, outbreaks, epidemics, and pandemics are unlikely to occur.

Component 3-"oil and gas chemistry": The risk of a decrease in OPEC's share in the market until 2035 has the greatest weight. The emergence of this risk is directly related to the development of some petrochemical clusters. Under the \#StayHome scenario, the impact on long-term plans under climate change containment programs is evident, which could increase OPEC's share and have a de facto positive effect on cluster development.

Component 4-"recycling and disposal": This is the dependence of the improvement of waste processing and the development of electrified transport with tax incentives for manufacturers of equipment and technology. The threat of a slowdown in the development of state programs manifests itself in the \#StayHome and the \#StayAlone scenarios.

The components from five to nine of the generalized factorial model of scenario risks are shown in Figure 7. 


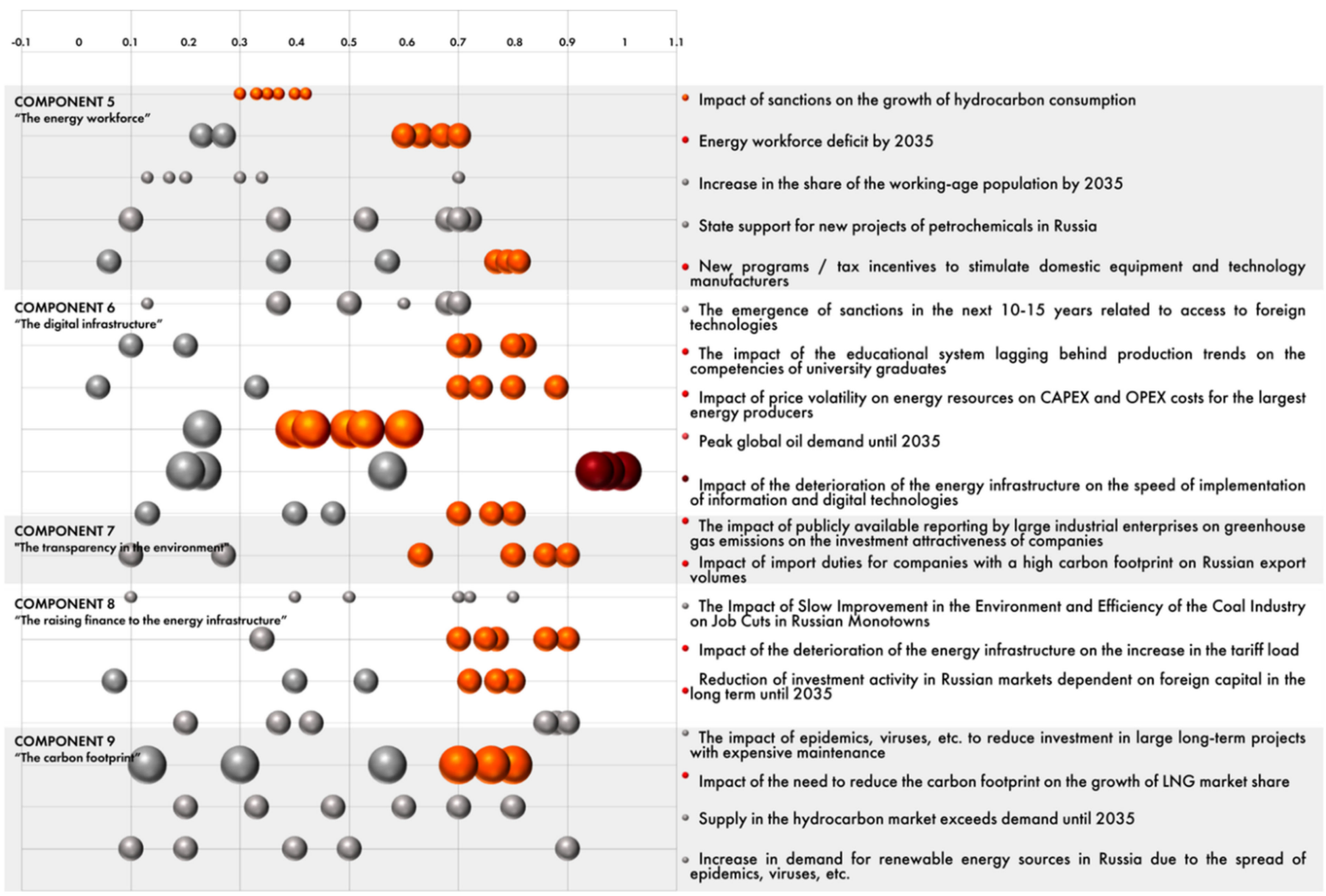

Figure 7. The generalized factorial model of scenario risks (components five to nine) [56].

Component 5-"energy workforce": This is the risk of a shortage of human resources, which is strongly associated with long-term government projects and programs as well as the impact of sanctions on consumption of fossil fuel. The concentration of probability and severity of consequences in the area of mean values emphasizes that sanctions will persist to varying degrees for all scenarios. Long-term training programs are among the measures that need to be launched without focusing on any particular scenario.

Component 6-"digital infrastructure": This is the risk of the negative impact of the volatility of oil price on the costs of producing companies, which can either drive oil out of the markets or give a push to producers for modernizing their production in order to increase its efficiency, flexibility, and sustainability based on the utilization of digital technologies. However, in the \#StayHome scenario, there are significant risks of underfunding the infrastructure, which will strongly affect the development of the digital technologies. Given the significant time required to mitigate these risks, the link "infrastructure-digital technologies" must be considered at once as a whole. This component has the greatest impact on the sector of the fossil energy in any scenario (dark red spheres in Figure 7).

Component 7- "transparency in the environment": This is the relationship between the work of companies in the field reducing negative impact on the environment and an increase in the attractiveness of investments, and the need for such work is manifested in any of the scenarios under consideration.

Component 8-"raising financing the energy infrastructure": This is the risk of a decrease in investment activity, which leads to an increase in the deterioration of the energy infrastructure. This will result in an increase of the burden of the tariff. This risk manifests itself even in the \#StayEffective scenario, which underlines the need for proactive measures in order to maintain active investments and to prevent underfunding of infrastructure projects. Since the response time to these risks is significant, immediate action is required.

Component 9-"carbon footprint": This is the need to reduce the carbon footprint regardless of the current scenario. The negative impact of new pandemics on large renew- 
able energy and LNG projects will increase the time needed to respond to risks associated with increased emissions.

As can be seen from the results of the factor analysis, all risks are interrelated, and they appear in each of the scenarios. Grouping risks allowed us to understand which areas should be the comprehensively considered development programs in the sector of fossil energy.

Based on our factor analysis, programs for the development of the energy sector were formed in order to combine nine risk components into one, correlated with the technological trends that need to be developed to take preventive measures in order to avoid negative consequences in one of the possible scenarios.

\subsection{The Programs of Development of the Energy Sector}

Each of the nine programs offered below were named according to their respective component. The programs were treated as a whole with the overall goal of making the transition to sustainable fossil energy development with the enhancement of five attributes: flexibility, security of supply, speed, quality, and environmental efficiency.

The programs for the development of the energy sector are presented in Table 5.

Table 5. The programs of development of the energy sector.

\begin{tabular}{|c|c|c|}
\hline & Name of Program & Preventive Measures \\
\hline 1 & Efficient energy & $\begin{array}{ll}\text { - } & \text { Incentives and investments in technologies for the development of Arctic fields } \\
\text { - } & \text { Development of low-tonnage LNG production at gas distribution stations } \\
\text { (GDSs) and virtual pipeline systems [68,69] } \\
\text { - } \quad \text { Digital platforms for personalized energy managers based on artificial } \\
\text { intelligence to manage energy consumption and encourage energy conservation }\end{array}$ \\
\hline 2 & High cost of production & $\begin{array}{l}\text { - Center for monitoring and forecasting safe and efficient development of mineral } \\
\text { deposits based on artificial intelligence } \\
\text { - Solving the problems of predicting the risks of any violation of the conditions of } \\
\text { safe operation of energy facilities }\end{array}$ \\
\hline 3 & Oil and gas chemistry & $\begin{array}{l}\text { - Formation of oil and gas chemical clusters on the territories of existing oil and } \\
\text { gas chemical complexes } \\
\text { - } \quad \text { Hydrogen program as part of the low-carbon development strategy [70] } \\
\text { - Legal regulation in accordance with international standards, development of } \\
\text { hydrogen clusters, education in the field of hydrogen technologies }\end{array}$ \\
\hline 4 & Recycling and disposal & $\begin{array}{l}\text { - Information database on the best available waste recycling technologies based } \\
\text { on big data technology } \\
\text { - } \quad \text { Legal regulation of the treatment of secondary resources } \\
\text { - } \quad \begin{array}{l}\text { Support for the development of research in the field of carbon chemistry } \\
\text { (technologies carbon capture, storage and use, control of methane emissions) }\end{array} \\
\text { - } \quad \begin{array}{l}\text { Development management and integration of electrified transport into the } \\
\text { energy system of cities based on an intelligent platform of the Internet of Things }\end{array} \\
\text { - Tax incentive program for the import of electric vehicles }\end{array}$ \\
\hline 5 & Energy workforce & $\begin{array}{l}\text { - DiLAB Digital Lab Spaces integrating infrastructure, processes, and people to } \\
\text { master digital competencies } \\
\text { - Conducting international conferences on artificial intelligence in energy, oil and } \\
\text { gas, and mining sectors } \\
\text { - Attracting foreign scientists on the basis of grant support for research in the field } \\
\text { of improving the efficiency of production of fossil fuel } \\
\text { - Export of education: programs of international summer schools for students on } \\
\text { the best technologies for energy, oil and gas, and mining industries }\end{array}$ \\
\hline
\end{tabular}


Table 5. Cont.

\begin{tabular}{|c|c|c|}
\hline & Name of Program & Preventive Measures \\
\hline 6 & Digital infrastructure & $\begin{array}{l}\text { - } \quad \begin{array}{l}\text { Formation of a unified database of digital models of energy infrastructure } \\
\text { - }\end{array} \text { Development of computing power and the data processing center for modeling } \\
\text { the behavior of the infrastructure and forecasting its condition } \\
\text { - } \quad \text { Stimulating technologies ensuring the flexibility of oil, gas, and coal production, } \\
\text { transportation, storage, and sales chains } \\
\text { - Creation of a scientific data factory for a mineral resource complex based on big } \\
\text { data technologies "Digital Energy Data Factory" } \\
\text { - Creation of the digital platform "EnergyRF" [56]. This is a system of mutually } \\
\text { beneficial algorithmic relationships between a large number of independent } \\
\text { participants in mining, oil and gas, and electric power industries, carried out in a } \\
\text { single information environment [56] } \\
\text { Creation of the digital platform "Genesis Drive". It is an intelligent platform for } \\
\text { lifecycle of power and electromechanical equipment based on digital } \\
\text { technologies }\end{array}$ \\
\hline 7 & $\begin{array}{l}\text { Transparency in the } \\
\text { environment }\end{array}$ & $\begin{array}{l}\text { - } \begin{array}{l}\text { Repayment of the interest rate of the investment loan at the expense of } \\
\text { income tax } \\
\text { - }\end{array} \text { Accelerated depreciation of best available technologies equipment } \\
\text { - } \quad \text { Reduction of impact costs following the implementation of best available } \\
\text { technologies } \\
\text { - Creation of environmental funds for financing, international cooperation }\end{array}$ \\
\hline 8 & $\begin{array}{l}\text { Raising financing of the } \\
\text { energy infrastructure }\end{array}$ & $\begin{array}{l}\text { - The introduction of smart contract technology. This will allow one to conclude } \\
\text { and maintain commercial contracts and carry out investment research process } \\
\text { using Blockchain technology between the three circuits: processes (including } \\
\text { equipment) and users, markets, and data. } \\
\text { - Smart contracts can only exist in the environment of a digital platform with } \\
\text { unhindered access of executable code to smart contract objects (this task is } \\
\text { supported by an algorithm that tracks under specified conditions the } \\
\text { achievement or the breach of clauses and makes independent decisions based on } \\
\text { the programmed conditions) } \\
\text { - Formation of risk reduction programs for companies } \\
\text { - Localization of services and production of equipment }\end{array}$ \\
\hline 9 & Carbon footprint & $\begin{array}{l}\text { - Application of blockchain technology to control and capture emissions from the } \\
\text { production, transport, and use of energy } \\
\text { - Point-rating systems for assessing the carbon footprint and integration with } \\
\text { digital platforms } \\
\text { - Creation of a state fund for targeted investment in low greenhouse gas emitting } \\
\text { technologies }\end{array}$ \\
\hline
\end{tabular}

The nine programs were studied as a whole with the common objective of sustainable development of the energy sector.

\subsection{The Development of Digital Platfrom}

The programs of development of the energy sector are unified by the utilization of the digital technologies in the framework of a digital platform, "transformation of the energy sector for sustainable development".

The concept of such a digital platform implies the introduction of digital technologies in order to create new business models, services, and markets based on the capabilities of the digital economy:

Big data (BD): Big data first appeared in the work of Clifford Lynch in 2008 in a special feature of the journal Nature [71]. In his article, he took any array of heterogeneous data over 150 GB per day. The principle of operation of the big data technology is based on maximally informing the user about any phenomenon. The objective is to help make the right decision. In intelligent machines, a model of the future is built on the basis of an array of information, and then various options are simulated, and the results are tracked. This 
allows predicting equipment failures, optimizing dynamic pricing, reducing peak loads, and optimizing the integration of distributed generation into the system of power supply. Artificial intelligence (AI): $\mathrm{AI}$ is a foundational science in the same sense that physics is a foundational science [72,73]. AI systems are capable of analyzing and improving the quality of management. AI has the following principles of work in the energy sector:

- determines the likelihood of peak power consumption;

- allows better use of energy when demand is minimal;

- $\quad$ encourages users to actively use periods of low demand;

- $\quad$ increases the efficiency of operations;

- analyzes unstructured data, which now make up $80 \%$ of the information in companies;

- predicts the technical condition of the equipment;

- detects infrastructure failures;

- performs maintenance, data processing, and training and schedules optimization tasks.

Distributed ledger system (DLS): This represents a new paradigm for collection and transmission of information. A blockchain is a decentralized database within which the data are validated by the members of the network. The use of blockchain technology (smart contracts) has the advantage of eliminating intermediaries. The use of cryptocurrencies in peer-to-peer trading stimulates the growth of generation decentralization, and smart contracts simplify the management of electricity distribution [74-76].

Quantum technology (QT): When automating the collection of information, the system analyzes the flow of incoming data from a large number of separate sources, identifies the sequence of events, and determines the relationship between them. The predictive model allows predicting the state of electrical equipment as well as excluding secondary damages, because failure of adjacent elements are predicted in advance. This improves the efficiency of power systems by planning repairs, ensures an optimal allocation of resources, as well as reduces the time for responding and eliminating emergency modes [77].

Neurotechnology, virtual and augmented reality technologies (NVARTs): The purpose of this direction is the development of products in the field of communication for "man-machine" and "man-man" in augmented and virtual realities. It is based on neurointerfaces that increase the productivity of human-machine systems. This implies personnel and infrastructure support for complex research and development work, the implementation of educational programs for the training of scientific and engineering personnel, as well as personnel in the field of promoting new goods and services.

In addition to these groups of digital technologies, additional blocks are also distinguished, which also relate to technologies that are used in the energy sector: new production technologies, sensorics and robotics components, wireless technologies, and technologies for controlling the properties of biological objects.

The technologies presented above were combined into a digital platform, "transformation of the energy sector for sustainable development", shown in Figure 8. The formation of a smart consumer through digital technologies is a key challenge. The consumer is a key partner of the platform [56]. Interaction between market participants can be provided by the Internet of Energy (IoE) and the Internet of Things (IoT). 


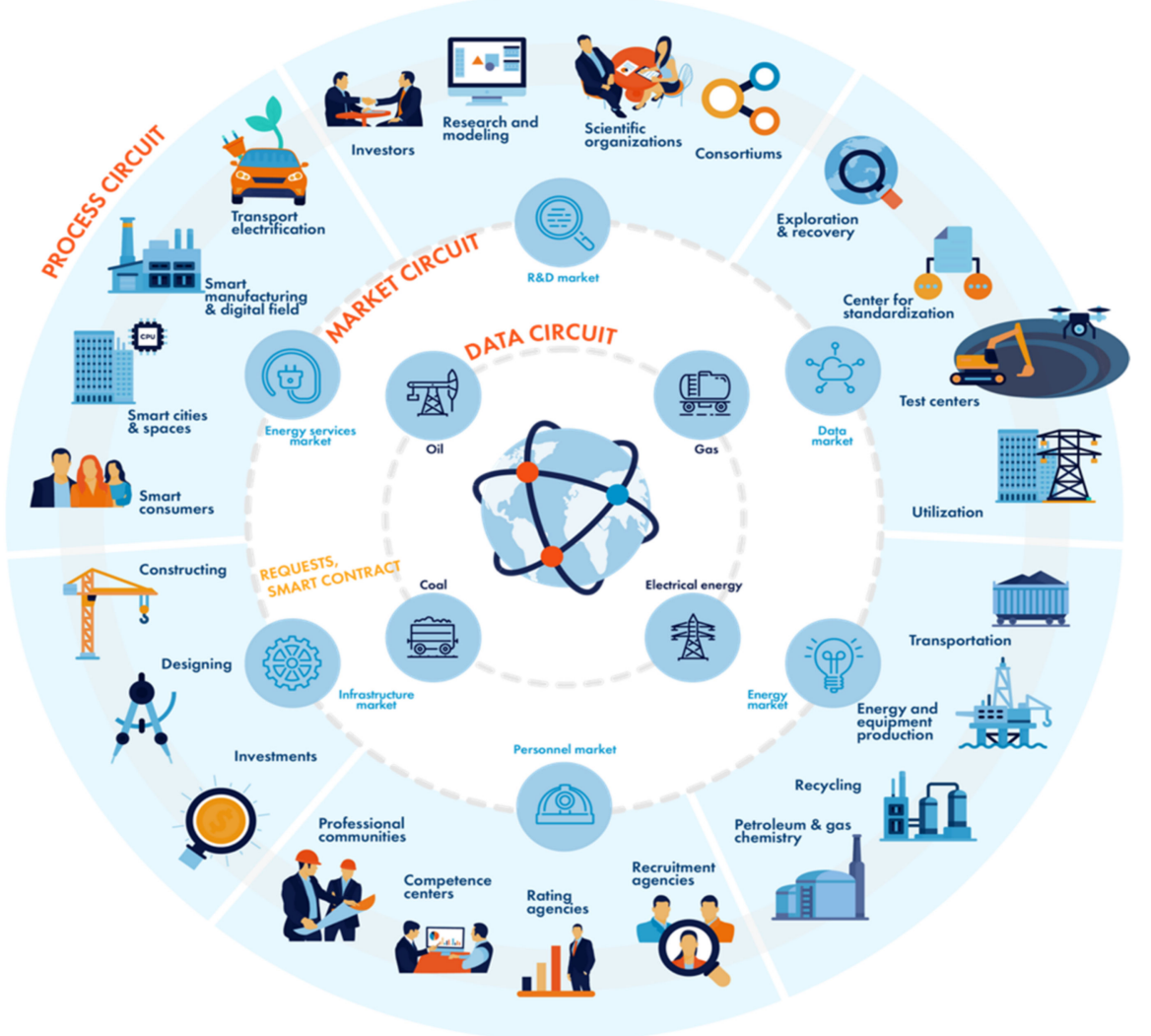

Figure 8. The digital platform, "transformation of the energy sector for sustainable development".

IoE and IoT complement the smart grid. The smart grid should be equipped with sensors that allow the exchange of a large amount of information, including weather conditions, electricity prices, and consumption at different times. This allows production, storage, and use of electricity more efficiently and provides an opportunity to regulate demand.

In other words, the IoE is the generation, the transmission, and the distribution of energy enhanced by digital control, monitoring, and telecommunications capabilities [78].

The number of online devices increased to 8.4 billion in 2017. It was estimated that, by 2020, it would consist of about 30 billion objects [79]. These devices include physical objects, vehicles, household appliances, and other objects that are embedded in electronics, software, sensors, and actuators. Apart from this, it is characterized by its internet connection. The IoT is a network of such devices through which they can exchange data and commands [80].

The analytics of the energy consumption provided by the user to the enterprise can potentially significantly improve efficiency and reduce congestion in the smart grid, which helps improve reliability of energy sector.

IoT can be used to transfer data reliably as follows:

1. In the field of electricity generation, IoT can be used to monitor the generation of electricity by various types of power plants (fossil fuels, wind, solar energy, biomass), gas emissions, energy storage, energy consumption, and prediction of the required capacity to supply consumers.

2. IoT can be used to determine power consumption, to dispatch, monitor, and protect power lines, substations, and towers, and to control and monitor equipment.

3. IoT can be used on the consumer side at the level of smart meters for measuring various types of parameters, energy consumption, interaction between different networks, charging and discharging electric vehicles, and managing consumption. 
There are multiple exchanges of information in the data circuit, the market circuit, and the process circuit in any direction and between any sphere.

The digital platform includes the following programs:

- The smart contract is complete automation and reliability of the execution of contractual relations $[57,70]$. It is an ensemble of electronic algorithms that describe a set of conditions, the implementation of which entails some events in the real world and/or digital systems, as presented in a previous study [56]. Due to the consensus protocols embedded in the blockchain platform, it will be possible to share resources between several users in the format of exchanging energy resources between infrastructure, data, or using a common centralized storage. Blockchains and smart contracts can enable sharing of a single source based on digitally signed agreements.

- The data market is the basis for using artificial intelligence in predicting violations of the safe operation of energy facilities [71].

- $\quad$ Research \& Development markets and personnel markets appear to enhance the quality of education and science. These are the basis for the development of connections between the blocks of the platform.

- $\quad$ The energy services market is energy saving, demand management, integration of distributed energy sources, and other digital energy technologies.

- $\quad$ Energy market and infrastructure market provide access to investment and ownership of energy facilities at any level, which will affect the cost of consumption of energy and generate income.

The digital platform has the potential to be, between now and 2040, a driver of increased competition of developing countries, a paradigm shift to user-centered systems and direct interaction in economic, political, and social structures, and a strengthening of the role of the environmental agenda.

This will help achieve the SDGs so that the fossil fuel sector consequently becomes a reliable, sustainable pillar for the world in the context of any of the possible scenarios.

\section{Conclusions}

The study demonstrated the importance of analyzing the risks existing in the energy sector for conducting scenario forecasting. Political, sociocultural, economic, legal, technological, environmental, and commercial risks affecting the energy sector were thoroughly examined in the article. Based on the results of the generalized factorial model of scenario risks, the technological risk \#T15 (lack of developed energy infrastructure), political risk \#P2 (nationalization of industry), and sociocultural risk \#S4 (shortage of human resourses) were quantitatively determined to have direct influence, high probability of occurrence, and strong degrees of influence. These basics risks and their possible consequences issued from scenarios can not only slow down but can completely stop international programs related to the SDGs \#4 (quality education), \#7 (affordable and clean energy), \#8 (decent work and economic growth), \#9 (industry, innovation, and infrastructure), \#11 (sustainable cities and communities), \#12 (responsible comsumption and production), \#13 (climate action), \#14 (life below water), and \#15 (life on land) and therefore can pose a significant threat to the future energy transition. Based on the risk analysis, three contrasting scenarios named \#StayHome, \#StayAlone, and \#StayEffective for the development of fossil energy were identified. The generalized factorial model of scenario risks made it possible to not only consider each of the scenarios separately but to determine the main component for the development of the energy sector, regardless of the scenarios. This component is digital infrastructure. Based on the results of study, the nine programs for sustainable development of the energy sector were formed for each of the three scenarios for the implementation of a fossil energy policy using, for the sake of example, the specific case of the Russian Federation. Some measures for its implementation were also proposed and developed. These programs can be applied to any country, especially developing countries and countries with economies in transition. The programs were integrated into an interactive digital platform, "transformation of the energy sector for a sustainable development". 
The technologies of the Internet of Energy and the Internet of Things will ensure efficient interaction between participants in the energy sector. Due to the use of these technologies, the traditional roles of participants of the energy market will change. In particular, one participant will be able to combine the roles of a consumer of electrical energy and a producer of electrical energy, for example, on their own solar panels. Companies will save time and money with technology of digital twins, which is the backbone of the digital platform. Use of this technology provides the opportunity to reduce maintenance costs and emergency response time and run planned downtime. It will increase productivity by optimization of operating modes. Another of the effects of this technology is the ability to regulate the level of emissions, which will help to improve the environmental situation. Via the utilization of all these solutions, we can secure and optimize the combination of renewable energy and fossil energy, as their joint use is needed in the close future. It was confirmed that the energy sector needs to experience a total digital transformation to put all sources of energy together and effectively "keep the lights on".

Thus, this digital transformation becomes a key factor in the innovative development of the whole energy sector. This development of the energy sector is based on the synergy effect of deep integration of different types of energy brought into a close partnership with digital technologies. The digital platform should become not only a tool for achieving the SDGs but also a paramount actor in the transformation of fossil energy. The integration of digital and information technologies requires a daily summation in terms of flexibility, security of supply, speed, quality, environment, and efficiency. Thus, achieving the SDGs requires a deep integration of all types of resources with large-scale projects that bring countries together both in the direction of technology development and in the training of a workforce highly qualified to work at any level of the energy sector.

Author Contributions: Y.L.Z.: Methodology; D.E.B.: Formal Analysis, Investigation; A.D.B.: Conceptualization, Visualization; B.G.: Supervision, Writing-Review \& Editing; V.V.S.: Data Curation, Writing-Original Draft, Project Administration. All authors have read and agreed to the published version of the manuscript.

Funding: This research received no external funding.

Conflicts of Interest: The authors declare no conflict of interest.

\section{References}

1. Cantarero, M.M.V. Of renewable energy, energy democracy, and sustainable development: A roadmap to accelerate the energy transition in developing countries. Energy Res. Soc. Sci. 2020, 70, 101716. [CrossRef]

2. Bucci, A.; Eraydin, L.; Muller, M. Dilution effects, population growth and economic growth under human capital accumula-tion and endogenous technological change. J. Macroecon. 2019, 62, 103050. [CrossRef]

3. O'Sullivan, J.N. The social and environmental influences of population growth rate and demographic pressure deserve greater attention in ecological economics. Ecol. Econ. 2020, 172, 106648. [CrossRef]

4. Xu, Z.; Li, Y.; Chau, S.N.; Dietz, T.; Li, C.; Wan, L.; Zhang, J.; Zhang, L.; Li, Y.; Chung, M.G.; et al. Impacts of international trade on global sustainable development. Nat. Sustain. 2020, 3, 964-971. [CrossRef]

5. Scown, M.W. The Sustainable Development Goals need geoscience. Nat. Geosci. 2020, 13, 714-715. [CrossRef]

6. Rogelj, J.; McCollum, D.; Riahi, K. The UN's 'Sustainable Energy for All' initiative is compatible with a warming limit of $2{ }^{\circ} \mathrm{C}$. Nat. Clim. Chang. 2013, 3, 545-551. [CrossRef]

7. Balogun, A.-L.; Marks, D.; Sharma, R.; Shekhar, H.; Balmes, C.; Maheng, D.; Arshad, A.; Salehi, P. Assessing the Potentials of Digitalization as a Tool for Climate Change Adaptation and Sustainable Development in Urban Centres. Sustain. Cities Soc. 2019, 53, 101888. [CrossRef]

8. Simsek, Y.; Santik, W.G.; Anisuzzaman, M.; Urmee, T.; Bahri, P.A.; Escobara, R. An analysis of additional energy requirement to meet the sustainable development goals. J. Clean. Prod. 2020, 272, 122646. [CrossRef]

9. UN. Sustainable Energy Goals. 2020. Available online: https://www.un.org/sustainabledevelopment/ (accessed on 20 February 2021).

10. Reyers, B.; Selig, E.R. Global targets that reveal the social-ecological interdependencies of sustainable development. Nat. Ecol. Evol. 2020, 4, 1011-1019. [CrossRef]

11. Buonocore, J.J.; Choma, E.; Villavicencio, A.H.; Spengler, J.D.; Koehler, D.A.; Evans, J.S.; Lelieveld, J.; Klop, P.; Sanchez-Pina, R. Metrics for the sustainable development goals: Renewable energy and transportation. Palgrave Commun. 2019, 5, 136. [CrossRef] 
12. Iakovleva, E.; Lavrik, A.; Leskov, A. Assessing Solar Power Plant Efficiency Degradation Resulting from Heating. J. Ecol. Eng. 2018, 19, 115-119. [CrossRef]

13. BP. Energy Outlook 2020. Available online: https://www.bp.com/content/dam/bp/business-sites/en/global/corporate/pdfs/ energy-economics/energy-outlook/bp-energy-outlook-2020.pdf (accessed on 2 February 2021).

14. McKinsey Energy Insight of Global Energy Perspective 2020. Available online: https://www.mckinsey.com/ \{\}/media/ McKinsey/Industries/Oil\%20and\%20Gas/Our\%20Insights/Global\%20Energy\%20Perspective\%202019/McKinsey-EnergyInsights-Global-Energy-Perspective-2019_Reference-Case-Summary.ashx (accessed on 10 February 2021).

15. Spillias, S.; Kareiva, P.; Ruckelshaus, M.; McDonald-Madden, E. Renewable energy targets may undermine their sustainability. Nat. Clim. Chang. 2020, 10, 974-976. [CrossRef]

16. Sonter, L.J.; Dade, M.C.; Watson, J.E.M.; Valenta, R.K. Renewable energy production will exacerbate mining threats to biodiversity. Nat. Commun. 2020, 11, 1-6. [CrossRef] [PubMed]

17. World Economic Forum. Which Countries Could Gain the Most from Renewable Energy? 2018. Available online: https: //www.weforum.org/agenda/2018/05/these-20-water-stressed-countries-have-the-most-solar-and-wind-potential (accessed on 1 March 2021).

18. Litvinenko, V. Digital Economy as a Factor in the Technological Development of the Mineral Sector. Nat. Resour. Res. 2019, 29, 1521-1541. [CrossRef]

19. Zeppini, P.; Jeroen, C.J.M.; van den Bergh, J. Global competition dynamics of fossil fuels and renewable energy under climate policies and peak oil: A behavioral model. Energy Policy 2020, 136, 110907. [CrossRef]

20. Wang, Q.; Li, S.; Pisarenko, Z. Heterogeneous effects of energy efficiency, oil price, environmental pressure, R\&D investment, and policy on renewable energy-Evidence from the G20 countries. Energy 2020, 209, 118322. [CrossRef]

21. Brockway, P.E.; Owen, A.; Brand-Correa, L.I.; Hardt, L. Estimation of global final-stage energy-return-on-investment for fossil fuels with comparison to renewable energy sources. Nat. Energy 2019, 4, 612-621. [CrossRef]

22. Bazhin, V.Y.; Nikitina, L.N.; Savchenkov, S.A. Experience of mining specialists training at the chair of process and production automation of the mining university. Eur. Min. 2017, 1, 42-44. [CrossRef]

23. Dvoynikov, M.; Nutskova, M.; Blinov, P.A. Developments Made in the Field of Drilling Fluids by Saint Petersburg Mining University. Int. J. Eng. 2020, 33, 702-711. [CrossRef]

24. Huynh, T.L.D.; Hille, E.; Nasir, M.A. Diversification in the age of the 4th industrial revolution: The role of artificial intelligence, green bonds and cryptocurrencies. Technol. Forecast. Soc. Chang. 2020, 159, 120188. [CrossRef]

25. Kishita, Y.; Mizuno, Y.; Fukushige, S.; Umeda, Y. Scenario structuring methodology for computer-aided scenario design: An application to envisioning sustainable futures. Technol. Forecast. Soc. Chang. 2020, 160, 120207. [CrossRef]

26. Worku, G.; Teferi, E.; Bantider, A.; Dile, Y.T. Prioritization of watershed management scenarios under climate change in the Jemma sub-basin of the Upper Blue Nile Basin, Ethiopia. J. Hydrol. Reg. Stud. 2020, 31, 100714. [CrossRef]

27. Jefferson, M. Scenario planning: Evidence to counter 'Black box' claims. Technol. Forecast. Soc. Chang. 2020, 158, 120156. [CrossRef]

28. Linzenich, A.; Zaunbrecher, B.; Ziefle, M. "Risky transitions?” Risk perceptions, public concerns, and energy infrastructure in Germany. Energy Res. Soc. Sci. 2020, 68, 101554. [CrossRef]

29. Zhong, Q.-C. Synchronized and Democratized Smart Grids To Underpin The Third Industrial Revolution. IFAC-PapersOnLine 2017, 50, 3592-3597. [CrossRef]

30. Soares, N.; Martins, A.; Carvalho, A.; Caldeira, C.; Du, C.; Castanheira, E.; Rodrigues, E.; Oliveira, G.; Pereira, G.I.; Bastos, J.; et al. The challenging paradigm of interrelated energy systems towards a more sustainable future. Renew. Sustain. Energy Rev. 2018, 95, 171-193. [CrossRef]

31. Oil and Gas Industry Expansions Could Add as Much Greenhouse Gas Pollution as 50 Coal Plants by 2025; Environmental Integrity Project: Washington, DC, USA, 2020.

32. Liu, Z.; Ciais, P.; Deng, Z.; Davis, S.J.; Zheng, B.; Wang, Y.; Cui, D.; Zhu, B.; Dou, X.; Ke, P.; et al. Carbon Monitor, a near-real-time daily dataset of global CO2 emission from fossil fuel and cement production. Sci. Data 2020, 7, 1-12. [CrossRef] [PubMed]

33. World Development Indicators Database, World Bank 2021. Available online: https:// databank.worldbank.org/source/worlddevelopment-indicators (accessed on 12 February 2021).

34. UN. Data Sources, Country Classifications, and Aggregation Methodology. United Nations. 2020. Available online: https: //www.un.org (accessed on 11 February 2021).

35. EIA. International Energy Outlook 2019 with Projections to 2050. U.S. Energy Information Administration. 2019. Available online: https:// www.eia.gov/ outlooks/ieo/pdf/ieo2019.pdf (accessed on 2 February 2021).

36. Umar, M.; Ji, X.; Kirikkaleli, D.; Alola, A.A. The imperativeness of environmental quality in the United States transportation sector amidst biomass-fossil energy consumption and growth. J. Clean. Prod. 2020, 285, 124863. [CrossRef]

37. Pashke, M. Legal Aspects of Germany's New Energy Policy. J. Min. Inst. 2017, 226, 487.

38. Frenzy, F. How the Fracking Industry is Threatening the Planet 2014/Friends of the Earth Europe. 2014. Available online: http://www.foeeurope.org/sites/default/files/publications/fracking_frenzy_0.pdf (accessed on 25 February 2021).

39. EIA. Natural Gas Explained. 2020. Available online: https://www.eia.gov/energyexplained/natural-gas/data-and-statistics.php (accessed on 2 February 2021).

40. Nevskaya, M.; Seleznev, S.G.; Masloboev, V.A.; Klyuchnikova, E.M.; Makarov, D.V. Environmental and Business Challenges Presented by Mining and Mineral Processing Waste in the Russian Federation. Minerals 2019, 9, 445. [CrossRef] 
41. Tarazanov, I.G.; Gubanov, D.A. Results of the work of the coal industry in Russia for January-December 2020. Coal 2020, 3, 27-43. (In Russian)

42. FORTUM-For a Cleaner World. Fortum Investor Relations and Financial Communications. 2020. Available online: https: / / www.fortum.com (accessed on 12 February 2021).

43. Russian Export of the Most Important Goods. Federal Customs Service of the Russian Federation. 2019. Available online: http:/ / customs.ru (accessed on 23 February 2021). (In Russian).

44. Statistical Yearbook of World Energy. Enerdata. 2019. Available online: https:/ /yearbook.enerdata.ru (accessed on 4 February 2021). (In Russian).

45. Di Silvestre, M.L.; Favuzza, S.; Sanseverino, E.R.; Zizzo, G. How Decarbonization, Digitalization and Decentralization are changing key power infrastructures. Renew. Sustain. Energy Rev. 2018, 93, 483-498. [CrossRef]

46. BloombergNEF. New Energy Forecast 2020. Available online: https://about.bnef.com/new-energy-outlook/ (accessed on 25 February 2021).

47. Rissse, M.; Rentyuk, V. Several steps to effective data processing from oil and gas fields. Control Eng. 2019, 81, 20-24.

48. High-Efficiency, Low-Emissions Coal Plants: Come HELE or High Water/Transform. Energy Outlook. 2018. Available online: https: / / www.ge.com (accessed on 2 February 2021).

49. Sustainability Report 2018. Royal Dutch Shell. 2018. Available online: https://reports.shell.com/sustainability-report/2018/ (accessed on 2 December 2020).

50. Global Energy Highlights 2019. Enerdata. 2020. Available online: https:/ /yearbook.enerdata.net (accessed on 27 February 2021).

51. Bardanov, A.I.; Vasilkov, O.S.; Pudkova, T.V. Modeling the process of redistributing power consumption using energy storage system with various configurations to align the electrical loads schedule. In Proceedings of the International Conference on Innovations, Physical Studies and Digitalization in Mining Engineering 2020, IPDME 2020, St. Petersburg, Russia, 23-24 April 2020; Volume 1753, pp. 1-9.

52. IRENA. Scenarios for the Energy Transition: Global Experience and Best Practices; IRENA: Abu Dhabi, United Arab Emirates, 2020.

53. The Global Electric Vehicle Market in 2020: Statistics E Forecasts; Virta: Helsinki, Finland, 2020.

54. IEA. Global EV Outlook 2019; International Energy Agency: Paris, France, 2020.

55. IEA. World Energy Outlook 2019. Available online: https://webstore.iea.org/world-energy-outlook-2019 (accessed on 28 February 2021).

56. Shabalov, M.Y.; Zhukovskiy, Y.L.; Buldysko, A.D.; Gil, B.; Starshaia, V.V. The influence of technological changes in energy efficiency on the infrastructure deterioration in the energy sector. Energy Rep. 2021, 7, 2664-2680. [CrossRef]

57. Shove, E. Time to rethink energy research. Nat. Energy 2020, 6, 118-120. [CrossRef]

58. Zhukovskiy, Y.L.; Starshaia, V.V.; Batueva, D.E.; Buldysko, A.D. Analysis of technological changes in integrated intelligent power supply systems. Innovation-Based Development of the Mineral Resources Sector: Challenges and Prospects. In Proceedings of the 11th Russian-German Raw Materials Conference, Potsdam, Germany, 7-8 November 2018; pp. $249-258$.

59. Chen, K.; Ren, Z.; Mu, S.; Sun, T.; Mu, R. Integrating the delphi survey into scenario planning for China's renewable energy development strategy towards 2030. Technol. Forecast. Soc. Chang. 2020, 158, 120157. [CrossRef]

60. Jones, A.W. Perceived barriers and policy solutions in clean energy infrastructure investment. J. Clean. Prod. 2015, 104, 297-304. [CrossRef]

61. Jonek-Kowalska, I. Efficiency of Enterprise Risk Management (ERM) systems. Comparative analysis in the fuel sector and energy sector on the basis of Central-European companies listed on the Warsaw Stock Exchange. Resour. Policy 2019, 62, 405-415. [CrossRef]

62. Pashkevich, M.A.; Petrova, T.A. Technogenic impact of sulfide-containing wastes produced by ore mining and processing at the Ozernoe deposit: Investigation and forecast. J. Ecol. Eng. 2017, 18, 127-133. [CrossRef]

63. Vaillancourt, K.; Bahn, O.; Frenette, E.; Sigvaldason, O. Exploring deep decarbonization pathways to 2050 for Canada using an optimization energy model framework. Appl. Energy 2017, 195, 774-785. [CrossRef]

64. EIA. Natural Gas-Fired Generation has Increased in Most U.S. Regions Since 2015. U.S. Energy Information Administration. 2020. Available online: https:/ / www.eia.gov / (accessed on 2 February 2021).

65. Cleopatra, W.A.; André, W. Varimax Rotation Based on Gradient Projection Is a Feasible Alternative to SPSS. Front. Psychol. 2019, 10, 645. [CrossRef]

66. Hew, A.; Perrons, R.K.; Washington, S.; Page, L.; Zheng, Z. Using digital technologies to deliver scenarios to geographically dispersed stakeholders: Lessons learned from the transportation sector. Futures 2020, 120, 102567. [CrossRef]

67. Tcvetkov, P.; Cherepovitsyn, A.; Makhovikov, A. Economic assessment of heat and power generation from small-scale lique-fied natural gas in Russia. Energy Rep. 2020, 6, 391-402. [CrossRef]

68. Coady, D.; Parry, I.; Sears, L.; Shang, B. How large are global fossil fuel subsidies? World Dev. 2017, 91, 11-27. [CrossRef]

69. Shell. LNG Outlook 2019; Shell: Hague, The Netherlands, 2020.

70. Zhukovskiy, Y.; Malov, D. Concept of Smart Cyberspace for Smart Grid Implementation. J. Phys. Conf. Ser. $2018,1015,42067$. [CrossRef]

71. Lynch, C. How do your data grow? Nature 2008, 455, 28-29. [CrossRef]

72. Savage, N. The race to the top among the world's leaders in artificial intelligence. Nature 2020, 588, S102-S104. [CrossRef] 
73. Wetzstein, G.; Ozcan, A.; Gigan, S.; Fan, S.; Englund, D.; Soljačić, M.; Denz, C.; Miller, D.A.B.; Psaltis, D. Inference in artificial intelligence with deep optics and photonics. Nature 2020, 588, 39-47. [CrossRef]

74. Vazirani, A.A.; O’Donoghue, O.; Brindley, D.; Meinert, E. Blockchain vehicles for efficient Medical Record management. NPJ Digit. Med. 2020, 3, 1-5. [CrossRef]

75. Vranken, H. Sustainability of bitcoin and blockchains. Curr. Opin. Environ. Sustain. 2017, 28, 1-9. [CrossRef]

76. Howson, P. Tackling climate change with blockchain. Nat. Clim. Chang. 2019, 9, 644-645. [CrossRef]

77. Lu, H.; Guo, L.; Azimi, M.; Huang, K. Oil and Gas 4.0 era: A systematic review and outlook. Comput. Ind. 2019, 111, 68-90. [CrossRef]

78. Li, X.; Huang, Q.; Wu, D. Distributed large-scale Co-simulation for IoT-aided smart grid control. IEEE Access 2017, 5, 19951-19960. [CrossRef]

79. Rao, L.; Liu, X.; Xie, L.; Pang, Z. Hedging Against Uncertainty: A Tale of Internet Data Center Operations Under Smart Grid Environment. IEEE Trans. Smart Grid 2011, 2, 555-563. [CrossRef]

80. Ciavarella, S.; Joo, J.-Y.; Silvestri, S. Managing contingencies in smart grids via the Internet of Things. IEEE Trans. Smart Grid 2016, 7, 2134-2141. [CrossRef] 